\title{
Review Article \\ Development of PET and SPECT Probes for Glutamate Receptors
}

\author{
Takeshi Fuchigami, Morio Nakayama, and Sakura Yoshida \\ Department of Hygienic Chemistry, Graduate School of Biomedical Sciences, Nagasaki University, 1-14 Bunkyo-machi, \\ Nagasaki 852-8521, Japan \\ Correspondence should be addressed to Takeshi Fuchigami; t-fuchi@nagasaki-u.ac.jp
}

Received 28 June 2014; Accepted 29 August 2014

Academic Editor: Masahiro Ono

Copyright (C) 2015 Takeshi Fuchigami et al. This is an open access article distributed under the Creative Commons Attribution License, which permits unrestricted use, distribution, and reproduction in any medium, provided the original work is properly cited.

L-Glutamate and its receptors (GluRs) play a key role in excitatory neurotransmission within the mammalian central nervous system (CNS). Impaired regulation of GluRs has also been implicated in various neurological disorders. GluRs are classified into two major groups: ionotropic GluRs (iGluRs), which are ligand-gated ion channels, and metabotropic GluRs (mGluRs), which are coupled to heterotrimeric guanosine nucleotide binding proteins (G-proteins). Positron emission tomography (PET) and single photon emission computed tomography (SPECT) imaging of GluRs could provide a novel view of CNS function and of a range of brain disorders, potentially leading to the development of new drug therapies. Although no satisfactory imaging agents have yet been developed for iGluRs, several PET ligands for mGluRs have been successfully employed in clinical studies. This paper reviews current progress towards the development of PET and SPECT probes for GluRs.

\section{Introduction}

L-Glutamate is the primary endogenous excitatory neurotransmitter and glutamate receptors (GluRs) are implicated in a range of neurological functions within the mammalian central nervous system (CNS). Two distinct groups of GluRs have been identified: ionotropic receptors (iGluRs) and metabotropic receptors (mGluRs). iGluRs form ligand-gated ion channels and are classified into three subtypes based on their pharmacological properties: NMDA ( $N$-methyl-Daspartate receptors, NMDARs), AMPA ( $\alpha$-amino-3-hydroxy5-methylisoxazole-4-proprionic acid) receptors, and kainate receptors [1]. mGluRs are coupled to heterotrimeric guanosine nucleotide binding proteins (G-proteins) and include eight receptor subtypes, classified into three groups according to their sequence homology, signal transduction, and pharmacological profiles; group I includes mGluR1 and mGluR5, group II includes mGluR2 and mGluR3, and group III includes mGluR4, mGluR6, mGluR7, and mGluR8 [2]. Impaired regulation of GluRs may be involved in the pathophysiology of various brain disorders $[3,4]$. Positron emission tomography (PET) and single photon emission computed tomography (SPECT) imaging for GluRs are considered to be powerful tools for the evaluation of excitatory neurotransmission in the living brain, the study of the pathophysiology of related neurological disorders, and the quantification of GluR drug occupancy in vivo. To date, no specific radioligands for in vivo visualization of iGluRs have been identified. In contrast, there are several promising clinically useful PET ligands for mGluRs. This review summarizes current progress towards the development of PET and SPECT probes for GluRs, with a particular focus on NMDARs and mGluRs.

\section{NMDARs}

The NMDARs are iGluRs that play key roles in processes involving excitatory neurotransmission, including learning, memory, and synaptic plasticity $[5,6]$. Dysregulation of NMDARs has been identified in various neurological diseases, including epilepsy, ischemia, stroke, Parkinson's disease, Alzheimer's disease, Huntington's disease, and 
schizophrenia $[4,7,8]$. Activation of these receptors requires binding of glutamate and glycine and removal of $\mathrm{Mg}^{2+}$ blockade by membrane depolarization. NMDAR channel opening results in calcium influx into cells, followed by $\mathrm{Ca}^{2+}$ dependent signal transduction cascades that modulate many aspects of neuronal function $[1,9]$. Functional NMDARs are composed of two NR1 subunits, together with either two NR2 subunits or a combination of NR2 and NR3 subunits [1012]. NR1 subunits are ubiquitously distributed throughout the brain. There are four types of the NR2 subunit (NR2A, NR2B, NR2C, and NR2D), with distinct distributions in the brain [13]. NR3 subunits can be activated by glycine alone. NR3A is expressed in the cortex and brainstem, while NR3B is distributed in the forebrain and cerebellum [14]. The glutamate binding site is present on the NR2 subunit, whereas the glycine binding site is located on NR1 or NR3 $[11,15,16]$. Polyamines are allosteric potentiators of NMDARs containing NR2B subunits, presumably through recognition of the NR1 and NR2B dimer interface [17]. It is known that aliphatic cyclic amine groups strongly inhibit NMDAR activity in a noncompetitive and voltage-dependent manner $[18,19]$. Negative modulators of NR2B, including ifenprodil and its derivatives, have been found to bind at the interface between the NR1 and NR2B subunits [20]. The main strategy for development of PET and SPECT ligands is the structural modification of NMDA receptor antagonists, including channel blockers, glycine site antagonists, and NR2B negative modulators. Because most competitive antagonists of the glutamate binding site have shown low selectivity and poor blood-brain barrier (BBB) permeability $[1,21]$, there are no reported radioligands interacting with this region of the NMDAR.

\subsection{Imaging Probes for the NMDAR Channel Blocker Binding} Site. Open channel blockers of NMDARs, such as (+)-10, 11-dihydro-5-methyl-5H-dibenzo[a,d] cyclohepten-5,10-diyldiammonium maleate (MK-801) and phencyclidine (PCP) derivatives, have been reported to bind to NMDARs in an activation-dependent manner [22, 23]. Thus, numerous in vivo imaging agents have been developed to interact with the PCP binding site, as this enables evaluation of the distribution of functional NMDARs in the brain under normal and pathological states. These agents include PCP, MK-801, ketamine, memantine, and diarylguanidine derivatives. $\left[{ }^{18} \mathrm{~F}\right] \mathbf{1}$ (Figure 1), a PCP derivative with an $\mathrm{IC}_{50}$ of $61 \mathrm{nM}$ for the ion channel site, showed an in vivo distribution that was consistent with NMDAR expression. Furthermore, coinjection of $1.7 \mu \mathrm{mol} / \mathrm{kg}$ of the high-affinity ion channel blocker, cis-2-hydroxymethyl-r-1-( $N$-piperidyl)1-(2-thienyl)cyclohexane (cis-HPTC), resulted in a reduction in the regional cerebral distribution of $\left[{ }^{18} \mathrm{~F}\right] \mathbf{1}$. However, this tracer was unsuitable for use as an NMDAR PET radioligand because of its high nonspecific binding in the brain [24]. A 3- $\left[{ }^{11} \mathrm{C}\right]$ cyano analog of MK-801 $\left(\left[{ }^{11} \mathrm{C}\right] \mathrm{MKC}\right.$, Figure 1$)$ has been reported as a PET ligand with excellent affinity for the channel blocker site $\left(K_{d}=8.2 \mathrm{nM}\right)$. This tracer showed highly specific binding and heterogeneous in vitro distribution in rat brain slices that was similar to the expression of NMDARs.
In PET studies, $\left[{ }^{11} \mathrm{C}\right] \mathrm{MKC}$ showed a rapid and high uptake into the brains of rhesus monkeys, with higher accumulation in the frontal cortex than in the cerebellar cortex. However, these distribution patterns correlated closely with regional cerebral blood flow and blocking with NMDAR antagonists did not affect the regional brain distribution of this tracer [25]. PCP and MK-801 analogs showed high nonspecific in vivo binding, probably due to their high lipophilicity. Diarylguanidines have been identified as highly potent NMDAR channel blockers, with less hydrophobicity than PCP and MK-801. Therefore, several radiolabeled diarylguanidine analogs have been reported as PET or SPECT ligands. $N$-(1-naphthyl)- $N^{\prime}$-(3-iodophenyl)- $N^{\prime}$-methylguanidine (CNS 1261, Figure 1) has been developed as a high-affinity SPECT ligand for the ion channel site $\left(K_{i}=4.2 \mathrm{nM}\right)$ with moderate lipophilicity $(\log D=2.19)$. In ex vivo autoradiographic studies, $\left[{ }^{125} \mathrm{I}\right] \mathrm{CNS} 1261$ showed 2.4-2.9-fold higher uptake by the hippocampus than by the cerebellum in normal rat brains. This accumulation pattern was consistent with the pattern of NMDAR expression. In addition, investigation of $\left[{ }^{125} \mathrm{I}\right] \mathrm{CNS} 1261$ binding in a mouse model of cerebral ischemia revealed that $\left[{ }^{125} \mathrm{I}\right] \mathrm{CNS} 1261$ showed 2 -fold higher uptake by the caudate nucleus in the ischemic hemisphere, as compared to the same region of the nonischemic hemisphere (Figure 2). This suggested that $\left[{ }^{125} \mathrm{I}\right] \mathrm{CNS} 1261$ bound selectively to activated NMDARs [26]. Based on this positive result, several clinical SPECT studies employing $\left[{ }^{123} \mathrm{I}\right] \mathrm{CNS} 1261$ have been performed. In healthy volunteers, no significant difference in the total distribution volume $\left(V_{T}\right)$ was observed between the NMDAR-rich regions (striatum, hippocampus, and frontal cortex) and the NMDAR-poor cerebellum [27, 28]. Numerous reports have suggested that hypofunction of NMDARs is associated with the pathophysiology of schizophrenia $[29,30]$. It is reported that drug-free patients with schizophrenia showed reduced binding of $\left[{ }^{123} \mathrm{I}\right] \mathrm{CNS} 1261$ in the left hippocampus relative to the whole cortex, compared with healthy controls [31]. In contrast, a separate study demonstrated that $V_{T}$ values of $\left[{ }^{123} \mathrm{I}\right] \mathrm{CNS} 1261$ in drug-free or typical antipsychotictreated schizophrenia patients did not differ significantly from those observed in the control group [32]. Therefore, these reports did not provide evidence to support the proposal that NMDARs could be imaged by SPECT using $\left[{ }^{123} \mathrm{I}\right] \mathrm{CNS}$ 1261. $N$-(2-chloro-5-thiomethylphenyl)- $N^{\prime}$-(3$\left[{ }^{11} \mathrm{C}\right]$ methoxy-phenyl)- $N^{\prime}$-methylguanidine $\quad\left[{ }^{11} \mathrm{C}\right] \mathrm{GMOM}$ (Figure 1) is a ${ }^{11} \mathrm{C}$-labeled diarylguanidine derivative with a high affinity for the ion channel site $\left(K_{i}=5.2 \mathrm{nM}\right)$. In PET studies conducted in baboons, $\left[{ }^{11} \mathrm{C}\right] \mathrm{GMOM}$ showed $\mathrm{BBB}$ permeability. However, brain distribution of $\left[{ }^{11} \mathrm{C}\right] \mathrm{GMOM}$ was almost homogeneous and preadministration of MK801 did not significantly change the regional $V_{T}$ [33]. Another diarylguanidine derivative, $\mathrm{N}$-(2-chloro-5-(methylmercapto)phenyl)- $N^{\prime}-\left[{ }^{11} \mathrm{C}\right]$ methylguanidine monohydrochloride $\left(\left[{ }^{11} \mathrm{C}\right] \mathrm{CNS}\right.$ 5161, Figure 1), had excellent affinity for the ion channel site $\left(K_{i}=1.9 \mathrm{nM}\right) \cdot\left[{ }^{3} \mathrm{H}\right] \mathrm{CNS} 5161$ showed a heterogeneous in vivo distribution in rat brain and a cortex/cerebellum ratio of 1.4. Pretreatment with 
<smiles>FCCc1ccc(C2(N3CCCCC3)CCCCC2)s1</smiles>

$\left[{ }^{18} \mathrm{~F}\right] \mathbf{1}$<smiles>CC12CC(N1)c1ccccc12</smiles>

$\left[{ }^{11} \mathrm{C}\right] \mathrm{MKC}$<smiles>CN(C(=N)Nc1cccc2ccccc12)c1cccc(I)c1</smiles>

$\left[{ }^{125 / 123} \mathrm{I}\right] \mathrm{CNS} 1261$<smiles>[Y9]c1cccc(N([R1])C(=N)Nc2cc(C)ccc2Cl)c1</smiles>

$\left[{ }^{11} \mathrm{C}\right]$ GMOM: $\mathrm{R}_{1}=\mathrm{CH}_{3}, \mathrm{R}_{2}=\mathrm{O}^{11} \mathrm{CH}_{3}$ $\left[{ }^{11} \mathrm{C}\right] \mathrm{CNS} 5161: \mathrm{R}_{1}={ }^{11} \mathrm{CH}_{3}, \mathrm{R}_{2}=\mathrm{SCH}_{3}$<smiles>Cc1cccc(N(C)C(=N)Nc2cc(SCC[18F])ccc2Cl)c1</smiles>

$\left[{ }^{18} \mathrm{~F}\right] \mathrm{GE}-179$

FIGURE 1: Chemical structure of imaging probes for channel blocker binding site of NMDARs.

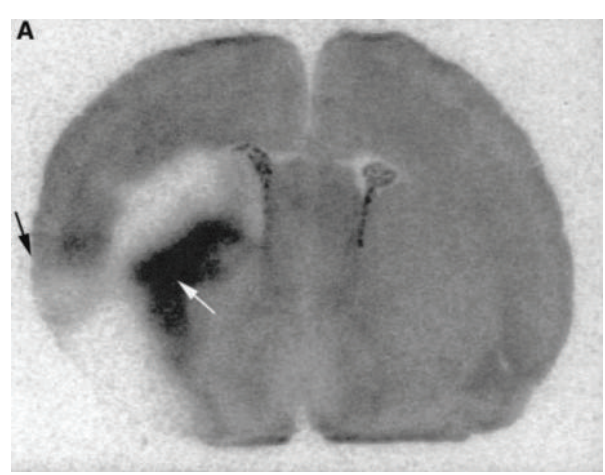

(a)

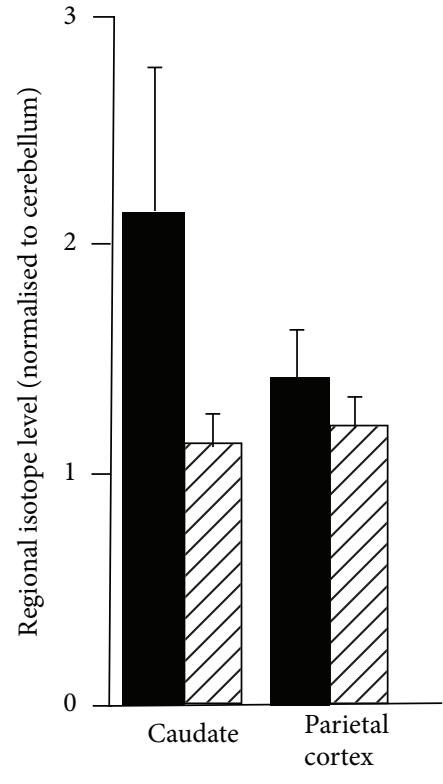

Ipsilateral

$\square$ Contralateral

(b)

FIgURE 2: Ex vivo autoradiograms of $\left[{ }^{125} \mathrm{I}\right] \mathrm{CNS} 1261$ in the caudate nucleus (white arrow) and cerebral cortex (black arrow) of rat brain (a). Quantified regional isotope levels normalized to cerebellum (b). The animals were injected with [ ${ }^{125}$ I]CNS 126115 min after permanent occlusion of the middle cerebral artery (left hemisphere) and sacrificed 120 min later [26].

NMDA increased the hippocampus/cerebellum ratio to 1.6-1.9, while MK801 reduced the ratios to close to 1.0 [34]. Clinical PET studies using $\left[{ }^{11} \mathrm{C}\right] \mathrm{CNS} 5161$ indicated that the largest uptake occurred in the putamen and thalamus and the lowest uptake was observed in the cerebellum, but relatively low levels of radioactivity were detected in the NMDAR-rich hippocampus [35]. Further investigations are necessary in order to provide consistent evidence that these diarylguanidines can be used as PET or SPECT radioligands for the channel blocker binding site of the NMDAR. Recently, 
<smiles>COc1cccc(NC(=O)/C=C/c2c(C(=O)O)[nH]c3cc(Cl)cc(Cl)c23)c1</smiles>

$\left[{ }^{11} \mathrm{C}\right] 3 \mathrm{MPICA}$<smiles>[R]c1cc(Cl)cc2[nH]c(=O)c(-c3cccc(O[CH])c3)c(O)c12</smiles>

$\left[{ }^{11} \mathrm{C}\right] 3: \mathrm{R}=\mathrm{Et}$

$\left[{ }^{11} \mathrm{C}\right] 4: \mathrm{R}=\mathrm{I}$<smiles>O=C(Nc1ccc(N2CCN(CC[18F])CC2)cc1)NC1C[C@H](C(=O)O)Nc2cc(Cl)cc(Cl)c21</smiles>

$\left[{ }^{18} \mathrm{~F}\right] 2$<smiles>C[AlH]Nc1ccc(Cc2cccc(-c3c(O)c4ccc(Cl)cc4[nH]c3=O)c2)cc1</smiles>

$\left[{ }^{11} \mathrm{C}\right] 5$<smiles>COc1ccc(Cc2cccc(-c3c(OC)c4ccc(Cl)cc4[nH]c3=O)c2)cc1</smiles>

$\left[{ }^{11} \mathrm{C}\right] \mathrm{L}-703,717: \mathrm{R}=\mathrm{H}$

$\left[{ }^{11} \mathrm{C}\right]$ AcL703: $\mathrm{R}=\mathrm{Ac}$<smiles>CCc1cc(Cl)cc2[nH]c(=O)c(-c3cccc(NC)c3)c(O)c12</smiles>

$\left[{ }^{11} \mathrm{C}\right] 6$

FIGURE 3: Chemical structure of imaging probes for glycine binding site of NMDARs.

$\left[{ }^{18} \mathrm{~F}\right] \mathrm{GE}-179$ (Figure 1), a high-affinity channel blocker $\left(K_{i}=\right.$ $2.4 \mathrm{nM}$ ) [36], was radiolabeled and used for PET imaging in healthy human subjects. Although this tracer showed high brain uptake, the $V_{T}$ of each region was correlated to cerebral blood flow rather than the levels of NMDAR expression. Further characterization of $\left[{ }^{18} \mathrm{~F}\right] \mathrm{GE}-179$ may be necessary with in vivo PET studies using NMDAR-activated models [37].

2.2. Imaging Probes for the NMDAR Glycine Binding Site. A number of antagonists of the NMDAR glycine binding site have been developed as anticonvulsant and neuroprotective drugs [38]. Several radiolabeled cyclic amino acid derivatives, such as $\left[{ }^{11} \mathrm{C}\right]-3-[2-[(3-$ methoxyphenylamino) carbonyl $]$ ethenyl $]$-4,6-dichloroindole-2-carboxylic acid $\left(\left[{ }^{11} \mathrm{C}\right]\right.$ 3MPICA, Figure 3$)$ and $\left[{ }^{18} \mathrm{~F}\right] 2$, have excellent binding affinities for the glycine binding site $\left(K_{i}=4.8\right.$ and $6.0 \mathrm{nM}$, resp.). However, they showed poor in vivo BBB permeability and had brain accumulation patterns that were inconsistent with those of the NMDAR $[39,40]$. Since the low brain uptake of the cyclic amino acid derivatives was due to the highly polar charged carboxylate group, 4-hydroxyquinolones (4-HQs), which are carboxylic bioisosteres, have been investigated as high-affinity antagonists of the glycine binding site. 3-[3-(4-[ $\left[{ }^{11} \mathrm{C}\right]$ methoxybenzyl)phenyl]-4-hydroxy-7-chloroquinolin-2(1H)-one $\left(\left[{ }^{11} \mathrm{C}\right] \mathrm{L}-703,717\right.$, Figure 3$)$ has been developed as one of the most potent glycine site antagonists with a $4-\mathrm{HQ}$ backbone $\left(\mathrm{IC}_{50}=4.5 \mathrm{nM}\right.$ versus $\left.\left[{ }^{3} \mathrm{H}\right] \mathrm{L}-689,560\right)[41,42]$. In vivo experiments in mice showed poor initial brain uptake of $\left[{ }^{11} \mathrm{C}\right] \mathrm{L}-703,717\{0.32-0.36$ percent injected dose per gram of tissue $(\% \mathrm{ID} / \mathrm{g})$ at $1 \mathrm{~min}\}$ and high levels of radioactivity in the blood. Since warfarin administration caused a dose-dependent enhancement of the initial brain uptake of $\left[{ }^{11} \mathrm{C}\right] \mathrm{L}-703,717$, this tracer may have a high affinity for plasma protein warfarin binding sites. The accumulation of $\left[{ }^{11} \mathrm{C}\right] \mathrm{L}-703,717$ in the cerebrum was lower than that observed in the cerebellum at $30 \mathrm{~min}(0.20 \% \mathrm{ID} / \mathrm{g}$ versus $0.65 \% \mathrm{ID} / \mathrm{g}$ ). This distribution pattern was inconsistent with that of NMDAR expression. It should be noted that treatment with nonradioactive L-703,717 $(2 \mathrm{mg} / \mathrm{kg})$ only led to a significant reduction in the accumulation of $\left[{ }^{11} \mathrm{C}\right] \mathrm{L}$ 703,717 in the cerebellum [43]. In order to improve the BBB permeability of $\left[{ }^{11} \mathrm{C}\right] \mathrm{L}-703,717$, an acetyl derivative of L-703,717 ( $\left[{ }^{11} \mathrm{C}\right]$ AcL703, Figure 3) was developed as a prodrug radioligand. Initial brain uptake of $\left[{ }^{11} \mathrm{C}\right]$ AcL703 at 1 min was 2 -fold higher than that of $\left[{ }^{11} \mathrm{C}\right] \mathrm{L}-703,717$. In rat brain tissues, approximately $80 \%$ of $\left[{ }^{11} \mathrm{C}\right]$ AcL703had been metabolized to $\left[{ }^{11} \mathrm{C}\right] \mathrm{L}-703,717$ by $20 \mathrm{~min}$ after injection. In ex vivo studies, $\left[{ }^{11} \mathrm{C}\right] \mathrm{AcL} 703$ showed higher uptake in the cerebellum than in the cerebrum, consistent with the findings using $\left[{ }^{11} \mathrm{C}\right] \mathrm{L}-703,717$ [44]. Although a clinical PET study of $\left[{ }^{11} \mathrm{C}\right] \mathrm{AcL} 703$ was performed in healthy volunteers, cerebellar NMDARs could not be visualized by PET due to poor BBB penetration [45]. Other radiolabeled 4-HQs (3 and 4, Figure 3) with lower lipophilicity than $\left[{ }^{11} \mathrm{C}\right] \mathrm{L}-703,717$ have been developed as high-affinity radioligands for the glycine site $\left(K_{i}=7.2\right.$ and $\left.10.3 \mathrm{nM}\right)$. However, $\left[{ }^{11} \mathrm{C}\right] 3$ and $\left[{ }^{11} \mathrm{C}\right] 4$ did not exhibit a significant increase in brain uptake, as compared with $\left[{ }^{11} \mathrm{C}\right] \mathrm{L}-703,717$ [46]. The 4-HQs are acidic $\left(\mathrm{p} K_{a} \leqq 5\right)[42]$ and this may result in strong binding affinity for serum albumin and low BBB penetration. Thus, several amino 4-HQ derivatives with lower $\mathrm{p} K_{a}$ values were synthesized and evaluated as new PET radioligands for the glycine site. Methylamino derivatives of 4-HQs, 5 and $\mathbf{6}$ (Figure 3), showed high affinity for the glycine site $\left(K_{i}=\right.$ $11.7 \mathrm{nM}$ and $11.8 \mathrm{nM}$, resp.). Although the amine derivatives showed a much lower plasma protein binding ratio than 
the methoxy analogs, $\left[{ }^{11} \mathrm{C}\right] \mathbf{6}$ still displayed poor uptake into the brain [47]. Further structure-activity relationship studies are necessary to develop PET ligands for the glycine site with significantly improved BBB penetration. Furthermore, the brain distribution of imaging agents interacting with the glycine site can be greatly influenced by endogenous agonists. The NMDAR coagonists, glycine and D-serine, are present in the brain at micromolar levels. Glycine is ubiquitously distributed in the brain, while D-serine is predominantly found in the forebrain $[48,49]$. Levels of $\mathrm{D}$-serine are reportedly very low level in the cerebellum, because of the high expression level of an enzyme (D-amino acid oxidase, $\mathrm{DAO}$ ) that can degrade D-serine [50]. Consistent with the above reports, the $\left[{ }^{11} \mathrm{C}\right] \mathrm{L}-703,717$ signal in the cerebellum was diminished in mutant ddY/DAO-mice, which have high cerebellar D-serine levels (Figure 4). The refore, the low accumulation of $\left[{ }^{11} \mathrm{C}\right] \mathrm{L}-703,717$ in forebrain regions may reflect the strong inhibition caused by the high level of endogenous D-serine. Similarly, the higher uptake of $\left[{ }^{11} \mathrm{C}\right] \mathrm{L}-703,717$ in the cerebellum might be due to reduced binding inhibition by $\mathrm{D}$-serine [51].

\subsection{Imaging Probes for the NR2B Negative Modulator Binding} Site. NMDARs containing the NR2B subunit play a key role in various diseases, such as Parkinson's disease, Alzheimer's disease, and neuropathic pain. NR2B negative modulators have been developed for the treatment of these conditions $[17,52]$. Ligands targeting NR2B, including ifenprodil, are thought to bind at the interlobe cleft of the NR2B subunit [53]. CP-101,606 is a potent NMDAR antagonist that is highly selective for NR2B subunit-containing receptors, with $K_{d}$ values of $10 \mathrm{nM}$ [54]. Because CP-101,606 was identified as a potent NR2B negative modulator $\left(K_{i}=10 \mathrm{nM}\right)$, a ${ }^{11} \mathrm{C}$-labeled CP-101,606 derivative $\left(\left[{ }^{11} \mathrm{C}\right] 7\right.$, Figure 5) was developed as a PET ligand for the NR2B subunit [55]. In vitro binding of $\left[{ }^{11} \mathrm{C}\right] 7$ in rat brain slices was extremely high in the forebrain regions and very low in the cerebellum, with excellent specific binding (Figures 6(a) and 6(b)). This distribution pattern matched the NR2B subunit expression pattern [56]. However, in vivo studies in mice and monkeys demonstrated that this tracer showed homogeneous brain distribution and no specific binding of $\left[{ }^{11} \mathrm{C}\right] 7$ was observed (Figure 6(c)) [55]. A benzylpiperidine derivative, $\left[{ }^{11} \mathrm{C}\right] \mathbf{8}$ (Figure 5), has been developed as a selective high-affinity PET ligand for NR2B-containing NMDARs $\left(\mathrm{IC}_{50}=5.3 \mathrm{nM}\right)$. An in vivo study in rats showed poor brain uptake of $\left[{ }^{11} \mathrm{C}\right] \mathbf{8}$ and a localization that was inconsistent with the NR2B expression pattern [57]. [ $\left.{ }^{11} \mathrm{C}\right]$ EMD-95885 (Figure 5), a benzylpiperidine derivative with a high affinity for NR2B $\left(\mathrm{IC}_{50}=3.9 \mathrm{nM}\right)$, has been synthesized and evaluated. In vivo experiments in rats showed 59-fold higher brain uptake of $\left[{ }^{11} \mathrm{C}\right]$ EMD-95885 than of $\left[{ }^{11} \mathrm{C}\right] \mathbf{8}$. Although $\left[{ }^{11} \mathrm{C}\right]$ EMD95885 displayed homogeneous binding in brain tissues, a substantial reduction in brain uptake of $\left[{ }^{11} \mathrm{C}\right] \mathrm{EMD}$ 95885 was observed in the presence of nonradioactive $\mathbf{8}$ or ifenprodil, suggesting that some specific binding may occur in the brain. However, these blocking effects were observed in both NR2B-rich and NR2B-poor regions
[58]. The benzimidazole derivatives, 9 and $\mathbf{1 0}$ (Figure 5), have been identified as having high affinity for the NR2B subunit, with $K_{i}$ values of $7.3 \mathrm{nM}$ and $5.8 \mathrm{nM}$, respectively. Both $\left[{ }^{125} \mathrm{I}\right] \mathbf{9}$ and $\left[{ }^{125} \mathrm{I}\right] 10$ showed localizations consistent with NR2B subunit expression in rat brain slices. In vivo studies in mice found moderate brain uptake of $\left[{ }^{125} \mathrm{I}\right] \mathbf{9}$ and $\left[{ }^{125} \mathrm{I}\right] 10$ and distribution that was inconsistent with known NR2B expression patterns. However, treatment with nonradioactive 9 or the NR2B ligand, $\left[( \pm)-\left(R^{*}, S^{*}\right)\right]$-a-(4-hydroxyphenyl)$\beta$-methyl-4-(phenylmethyl)-1-piperidine propanol (Ro $25-6981$ ), caused $34 \%$ and $59 \%$ reduction in the brain/blood ratio of $\left[{ }^{125} \mathrm{I}\right] 9$, respectively. This tracer may therefore show partially specific binding to the NR2B subunit in vivo [59]. Further structural modification of $\mathbf{9}$ may contribute to the development of more promising imaging probes for the NR2B subunit. [2-(3,4-Dihydro- $1 \mathrm{H}$-isoquinolin-2yl)-pyridin-4-yl]-[ $\left[{ }^{11} \mathrm{C}\right]$ dimethylamine $\quad\left(\left[{ }^{11} \mathrm{C}\right]\right.$ Ro-647312, Figure 5) has been evaluated as a member of a different class of PET ligands with high affinity for the NR2B subunit $\left(K_{i}=8.0 \mathrm{nM}\right)$. However, in vivo biodistribution of $\left[{ }^{11} \mathrm{C}\right]$ Ro-647312 was almost homogeneous in the brain [60]. Several benzylamidines, such as $\left[{ }^{11} \mathrm{C}\right] 11$ (Figure 5), have been developed as high-affinity PET ligands for NR2B $\left(K_{i}=5.7 \mathrm{nM}\right.$ for 11). In vitro, $\left[{ }^{11} \mathrm{C}\right] 11$ showed excellent specific binding and a similar localization to that of NR2B. However, $\left[{ }^{11} \mathrm{C}\right] 11$ is an unsuitable imaging agent due to metabolic instability [61]. (3S,4R)-4-Methylbenzyl 3-fluoro-4-((pyrimidin-2-ylamino) methyl) piperidine-1-carboxylate (MK-0657) was developed as a highly potent NR2B antagonist $\left(\mathrm{IC}_{50}=3.6 \mathrm{nM}\right)$ for the treatment of neuropathic pain, Parkinson's disease, and major depression [17, 62]. Two radiofluorinated diastereoisomers of MK-0657 ([ $\left.{ }^{18} \mathrm{~F}\right]$ trans-MK-0657 and $\left[{ }^{18} \mathrm{~F}\right]$ cis-MK-0657, Figure 5) exhibited a localization pattern consistent with that of NR2B expression and very high specific binding for the NR2B modulator binding site. However, no further in vivo evaluations of these potential imaging agents have been reported [63].

\section{3. mGluRs}

mGluRs are widely expressed though the CNS and their activation leads to various effects on neuronal synaptic transmission via regulation of ion channels and signaling proteins. Dysregulation of mGluRs has been observed in various conditions affecting the CNS, such as anxiety [64], depression [65], Alzheimer's disease [66], schizophrenia [67], Parkinson's disease [68], and epilepsy [69]. Positive and negative modulators of mGluRs have therefore been developed for the treatment of these neurological diseases. Nuclear medicine imaging of mGluRs can be used for the investigation of a range of diseases, in addition to monitoring receptor occupancy by therapeutic agents. Thus, a considerable number of PET imaging probes for mGluRs have been reported. PET ligands for group I mGluRs (mGluR1 and 5) have been developed extensively and several of these have been confirmed as promising ligands in clinical studies. Recently, potential PET probes for mGluR2 (group II) have also been reported and have proceeded to phase I studies. No 


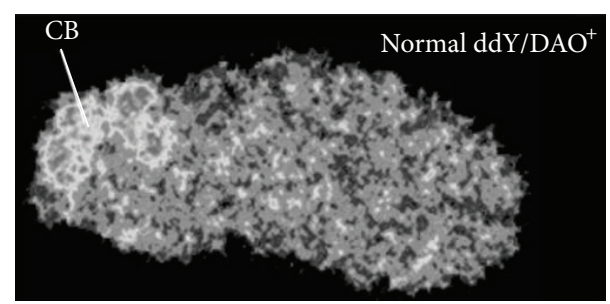

(a)

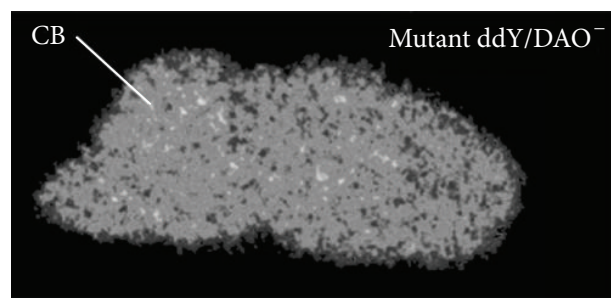

(b)

Figure 4: Ex vivo autoradiograms of $\left[{ }^{11} \mathrm{C}\right] \mathrm{L}-703,717$ in the brain of normal ddY/DAO+ (a) and mutant ddY/DAO-mice (b) 30 min after injection of $\left[{ }^{11} \mathrm{C}\right] \mathrm{L}-703,717$ and warfarin $(60 \mathrm{mg} / \mathrm{kg})[51]$.<smiles>COc1ccc(C2(O)CCN(C(C)C(O)c3ccc(O)cc3)CC2)cc1</smiles>

$\left[{ }^{11} \mathrm{C}\right] 7$

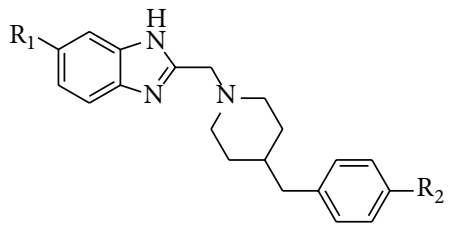

$\left[{ }^{125} \mathrm{I}\right] 9: \mathrm{R}_{1}=\mathrm{OH}, \mathrm{R}_{2}={ }^{125} \mathrm{I}$
$\left[{ }^{125} \mathrm{I}\right] \mathbf{1 0}: \mathrm{R}_{1}=\mathrm{NHSO}_{2} \mathrm{Me}, \mathrm{R}_{2}={ }^{125} \mathrm{I}$<smiles>O=c1[nH]c2ccc(C#CCN3CCC(Cc4ccccc4)CC3)cc2[nH]1</smiles><smiles>CN(C)c1ccnc(N2CCc3ccccc3C2)c1</smiles>

$\left[{ }^{11} \mathrm{C}\right]$ Ro-647312<smiles>CC(C)(C)[Mg][Mg]</smiles><smiles>COc1ccccc1CNC(=N)c1ccc(OC(F)(F)F)cc1</smiles>

$\left[{ }^{11} \mathrm{C}\right] \mathbf{1 1}$<smiles>Cc1ccc(COC(=O)C2CCC(CNc3ncccn3)C([PH+])C2)cc1</smiles>

FIGURE 5: Chemical structure of imaging probes for NR2B negative modulator binding site of NMDARs.

clinically useful PET ligands for group III mGluRs have been published, due to a lack of selectivity over other mGluRs.

\subsection{Imaging Probes for Group I mGluRs}

3.1.1. Physiology of Group I mGluRs. Group I mGluRs (mGluR1 and mGluR5) are predominantly expressed in the postsynaptic neuron. Their activation leads to increased neuronal excitability and they are involved in modulation of synaptic plasticity at glutamatergic synapses. They are coupled to $\mathrm{G}_{\mathrm{q}} / \mathrm{G} 11$ and upregulate inositol triphosphate and diacylglycerol levels via phospholipase $\mathrm{C}$ activation, triggering calcium mobilization, and activation of protein kinase $\mathrm{C}$ (PKC). In addition, group I mGluRs have been reported to be implicated in the mitogen-activated protein kinase (MAPK)/extracellular signal-regulated kin+ase
(ERK) and mammalian target of rapamycin (mTOR)/p70 S6 kinase pathways, which can regulate synaptic plasticity [70]. Complementary expression of mGluR1 and mGluR5 has been observed in the rodent brain. mGluR1 are found extensively throughout the brain, but are highly expressed in the cerebellar cortex, hippocampus, and thalamus. mGluR5 expression has been observed in the cerebral cortex, hippocampus, accessory olfactory bulbs, and nucleus accumbens [71]. mGluR1 antagonists have shown promising anxiolytic and antidepressant effects, whereas positive modulators of mGluR1 have been reported to be useful for the treatment of schizophrenia. Negative modulators of mGluR5 can be effective in the treatment of anxiety, fragile $\mathrm{X}$ syndrome, chronic pain, and depression [72]. In contrast, positive modulators of this receptor have potential for the treatment of schizophrenia [73]. 


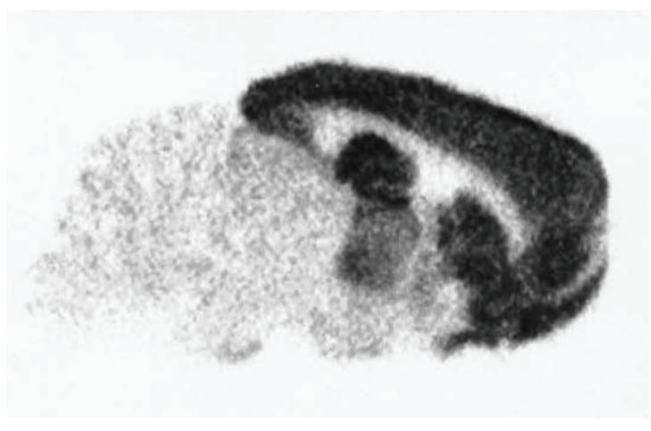

(a)

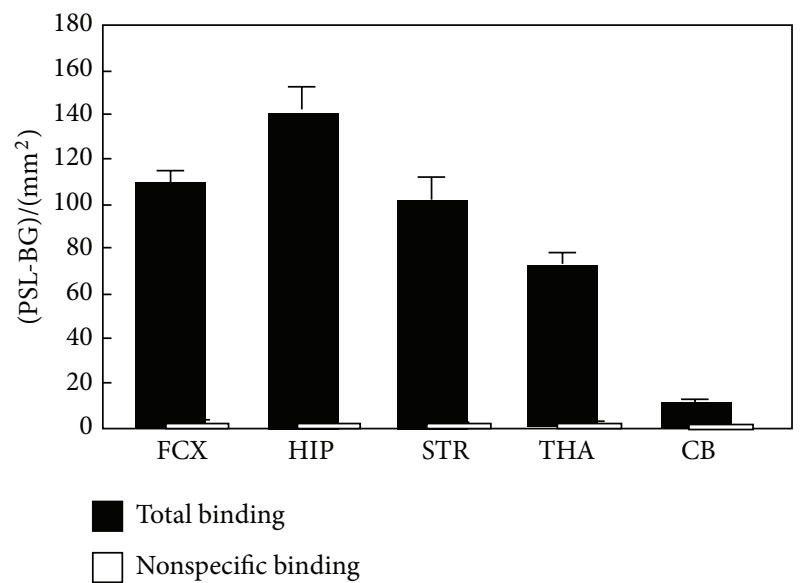

(b)

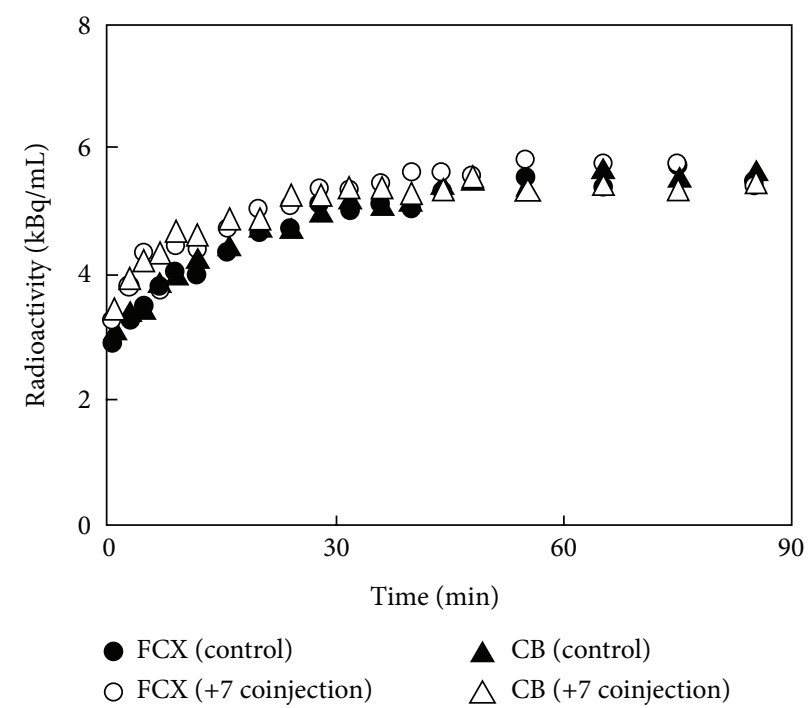

(c)

FIGURE 6: In vitro autoradiogram of $\left[{ }^{11} \mathrm{C}\right] 7$ (a) and quantified values of the autoradiogram in frontal cortex $(F T X)$, hippocampus $(H I P)$, striatum $(S T R)$, thalamus $(T H A)$, and cerebellum $(C B)(b)$. Nonspecific binding was determined in the presence of $(+) \mathrm{CP}-101,606(10 \mu \mathrm{M})$. (c) Time radioactivity curves in the monkey brain after administration of $\left[{ }^{11} \mathrm{C}\right] 7$. Nonradioactive $7(2 \mathrm{mg} / \mathrm{kg})$ was coinjected with $\left[{ }^{11} \mathrm{C}\right] 7 \mathrm{into}$ the same monkey [55].

3.1.2. Development of Imaging Probes for mGluR1. (3-Ethyl-2$\left[{ }^{11} \mathrm{C}\right]$ methyl-6-quinolinyl)(cis-4-methoxycyclohexyl)methanone ( $\left.{ }^{11} \mathrm{C}\right] J N J-16567083$, Figure 7$)$ has been developed as a high-affinity, selective mGluR1 ligand $\left(K_{i}=4.41 \mathrm{nM}\right.$ for rat mGluR1, $13.3 \mathrm{nM}$ for human mGluR1) [74]. Ex vivo studies using this ligand showed good brain uptake and a localization pattern consistent with mGluR1 expression. In addition, over $80 \%$ of the accumulation of $\left[{ }^{11} \mathrm{C}\right] J N J-16567083$ in the cerebellum was blocked by selective mGluR1 antagonists, while treatment with a selective mGluR5 antagonist produced no marked inhibition of its binding, indicating selectivity for mGluR1. In PET studies, it showed high specific binding in regions expressing mGluR1, indicating that $\left[{ }^{11} \mathrm{C}\right] \mathrm{JNJ}-$ 16567083 is bound to mGluR1 in the living rat brain [74]. An ${ }^{18}$ F-labeled JNJ-16567083 derivative ( $\left[{ }^{18} \mathrm{~F}\right] 12$, Figure 7$)$ was also reported to have a high affinity for mGluR1 $\left(K_{i}=\right.$
$1.77 \mathrm{nM}$ for rat mGluR1 and $24.4 \mathrm{nM}$ for human mGluR1). The in vivo localization of $\left[{ }^{18} \mathrm{~F}\right] \mathbf{1 2}$ in rats was similar to that of $\left[{ }^{11} \mathrm{C}\right] J N J-16567083$. The in vivo accumulation of $\left[{ }^{18} \mathrm{~F}\right] \mathbf{1 2}$ in the cerebellum was inhibited by pretreatment with a selective mGluR1 antagonist, but not by an mGluR2 antagonist (LY341495) or an mGluR5 antagonist (MPEP), indicating selectivity for mGluR1 in the living rat brain. However, PET studies in baboons found that $\left[{ }^{11} \mathrm{C}\right] J N J-16567083$ and $\left[{ }^{18} \mathrm{~F}\right] 12$ produced low brain signals, probably due to a lower receptor density in baboon brain than in rat brain [75]. These results suggested that less lipophilic and/or higher affinity mGluR1 ligands are necessary for successful imaging in the primate brain.

$N$-Cyclohexyl-6-\{[N-(2-methoxyethyl)-N-methylamino]methyl $\}$ - $N$-methylthiazolo [3,2-a]benzimidazole-2-carboxamide (YM-202074, Figure 7) has been reported as a 
<smiles>[R]c1nc2ccc(C(=O)C3CCC(OC)CC3)cc2cc1CC</smiles>

$\left[{ }^{11} \mathrm{C}\right] \mathrm{JNJ}-16567083: \mathrm{R}={ }^{11} \mathrm{CH}_{3}$

$\left[{ }^{11} \mathrm{C}\right] 12: \mathrm{R}={ }^{18} \mathrm{~F}$<smiles>Cc1c(-c2ccc3c(c2)CN(C(C)C)C3=O)nnn1-c1cccnc1P</smiles>

$\left[{ }^{18} \mathrm{~F}\right]$ FPIT<smiles>COCCN(C)Cc1ccc2c(c1)N1C=C(C(=O)N(C)C3CCCCC3)SC1N2</smiles>

$\left[{ }^{11} \mathrm{C}\right] \mathrm{YM} 202074$

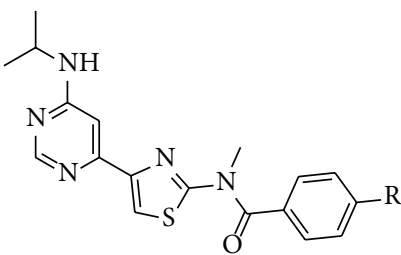

$\left[{ }^{11} \mathrm{C}\right]$ ITMM: $\mathrm{R}=\mathrm{O}^{11} \mathrm{CH}_{3}$

$\left[{ }^{11}\right.$ C]ITDM: $\mathrm{R}={ }^{11} \mathrm{CH}_{3}$

$\left[{ }^{18} \mathrm{~F}\right]$ FITM: $\mathrm{R}={ }^{18} \mathrm{~F}$<smiles>CCCN1Cc2cc(-c3nnn(-c4cccnc4F)c3C)ccc2C1=O</smiles>

$\left[{ }^{18} \mathrm{~F}\right] \mathrm{MK} 1312$

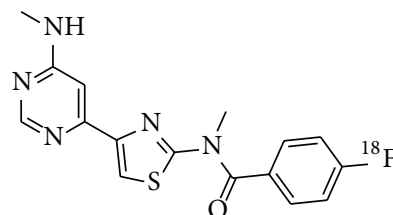

$\left[{ }^{18}\right.$ F $]$ FIMX

FIGURE 7: Chemical structure of imaging probes for mGluR1.

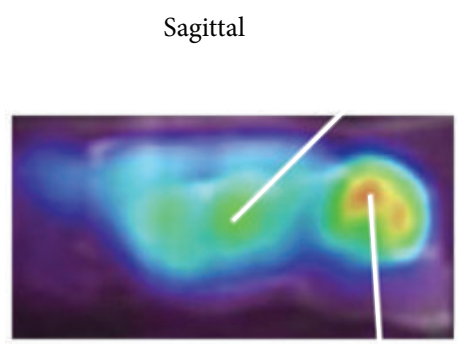

(a)

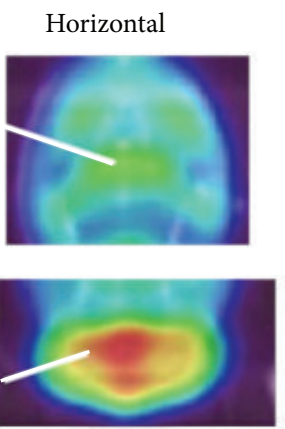

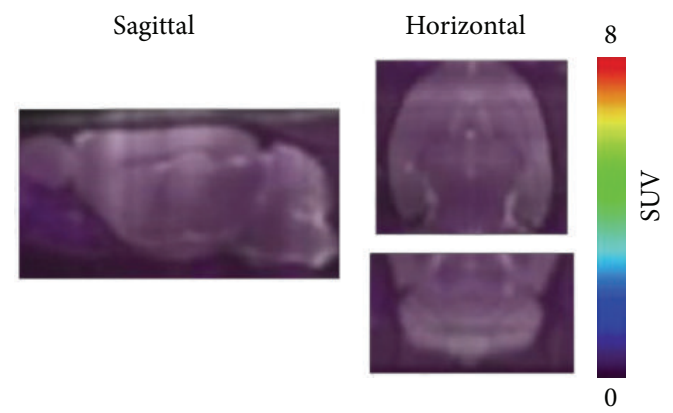

(b)

Figure 8: Sagittal PET images (0-60 min) of $\left[{ }^{11} \mathrm{C}\right] \mathrm{ITMM}$ in wild-type (a) and mGluR1 knockout (b) mice brains [83].

high-affinity, selective mGluR1 ligand $\left(K_{i}=4.8 \mathrm{nM}\right.$ for rat mGluR1) with lower lipophilicity than JNJ-16567083 $(\log D=$ 2.7 versus 3.38). Although $\left[{ }^{11} \mathrm{C}\right] \mathrm{YM}-202074$ showed in vitro accumulation consistent with mGluR1 expression in the rat brain, PET studies in rats using this ligand demonstrated a low brain uptake and localization that was inconsistent with mGluR1-rich regions. These findings may be attributed to rapid ligand metabolism and the subsequent influx of radiometabolites into the brain [76]. 1-(2-Fluoro-3pyridyl)-4-(2-propyl-1-oxoisoindoline-5-yl)-5-methyl-1H1,2,3-triazole (MK-1312, Figure 7) has been developed as a potent mGluR1 ligand $\left(\mathrm{IC}_{50}=4.3 \mathrm{nM}\right.$ for human mGluR1), with high selectivity and moderate lipophilicity $(\log P=$ 2.3). $\left[{ }^{18} \mathrm{~F}\right] \mathrm{MK}-1312$ displayed similar in vitro localization to that of mGluR1 and highly selective binding. PET studies of this ligand in rhesus monkeys demonstrated rapid uptake kinetics, with no significant defluorination in brain. In addition, binding was inhibited by the mGluR1 antagonist, MK-5435, in a dose-dependent manner [77]. Although these results indicated that $\left[{ }^{18} \mathrm{~F}\right] \mathrm{MK}-1312$ may be a promising PET ligand for mGluR1, no further clinical studies have been reported to date. 1-(2-Fluoro-3-pyridyl)-4-(2-isopropyl1-oxoisoindoline-5-yl)-5-methyl-1H-1,2,3-triazole (FPIT, Figure 7), an MK-1312 derivative, has been reported as a selective mGluR1 ligand with an $\mathrm{IC}_{50}$ of $5.4 \mathrm{nM}$ for human mGluR1 [77]. $\left[{ }^{18}\right.$ F]FPIT showed similar in vitro distribution to mGluR1 in both rat and monkey brains. In addition, its accumulation was selectively blocked by an mGluR1 ligand, indicating excellent specific binding (95\%). PET/magnetic resonance imaging (MRI) studies of this ligand in rats and monkeys demonstrated a distribution that was consistent with that observed in vitro. Brain accumulation of $\left[{ }^{18} \mathrm{~F}\right] \mathrm{FPIT}$ was significantly inhibited by nonradioactive FPIT and by the mGluR1-selective ligand JNJ-16259865 [78]. Although $\left[{ }^{18} \mathrm{~F}\right]$ FPIT has been demonstrated to be a prospective PET probe for mGluR1, further clinical studies have not yet been performed, probably due to the slow pharmacokinetics, and the influx of small levels of radiometabolites into the brain. 4-Fluoro- $N$-[4-[6-(isopropylamino)pyrimidin-4-yl]1,3-thiazol-2-yl]- $N$-methylbenzamide (FITM, Figure 7) was developed as a potent mGluR1 antagonist $\left(\mathrm{IC}_{50}=5.1 \mathrm{nM}\right)$ with high selectivity [79] and low lipophilicity $(\log D=1.46)$ 


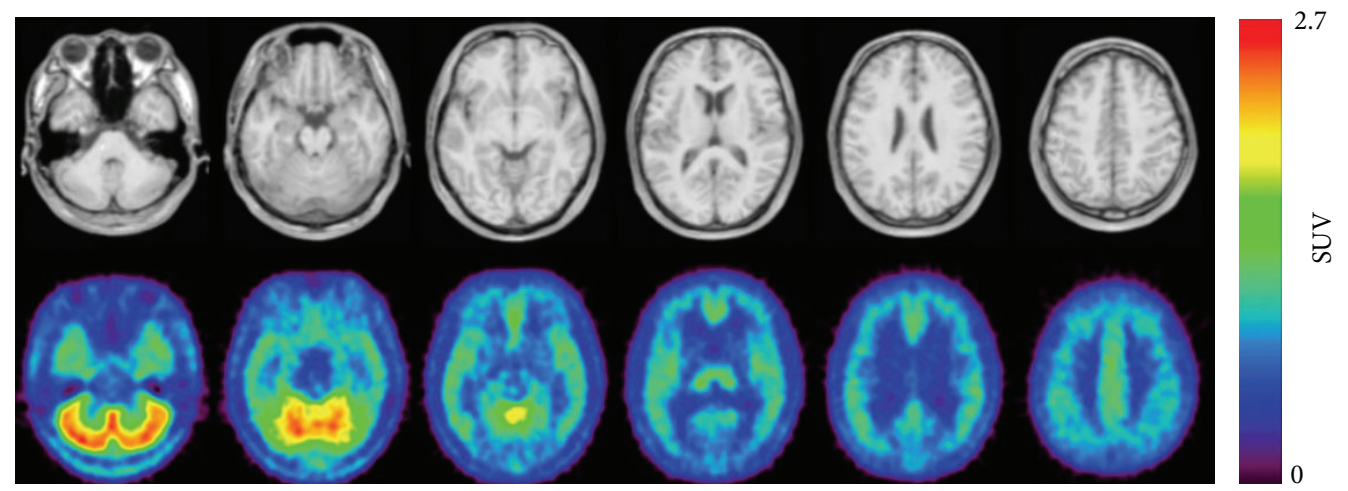

Figure 9: PET/MRI images of $\left[{ }^{11}\right.$ C]ITMM (40-60 min) obtained from 5 healthy human subjects. Upper: MR image and lower: averaged $\left[{ }^{11}\right.$ C]ITMM PET image [85].

[80]. In vitro and ex vivo binding of $\left[{ }^{18} \mathrm{~F}\right] \mathrm{FITM}$ matched the distribution of mGluR1, with high specific binding in mGluR1-rich regions [80]. $\left[{ }^{18}\right.$ F]FITM showed high brain uptake $(>7 \% \mathrm{ID} / \mathrm{g}$ in mice) and metabolic stability, with $95 \%$ intact $\left[{ }^{18} \mathrm{~F}\right]$ FITM detected in the rat brain $120 \mathrm{~min}$ after injection. Rat and monkey PET studies demonstrated a radioactive signal distribution consistent with that of the mGluR1, with very high specific binding. Kinetic analysis showed that the calculated $V_{T}$ values of $\left[{ }^{18} \mathrm{~F}\right] \mathrm{FITM}$ were also consistent with the localization of mGluR1 [81]. PET studies of $\left[{ }^{18} \mathrm{~F}\right]$ FITM in rat brain that included blocking experiments determined $B_{\max }$ and $K_{d}$ values in several brain regions with moderate mGluR1 expression, such as the thalamus, hippocampus, striatum, and cingulate cortex, consistent with the density of mGluR1 in these regions. However, because of its relatively slow kinetics, $B_{\max }$ and $K_{d}$ values of $\left[{ }^{18} \mathrm{~F}\right]$ FITM could not be measured in the mGluR1rich cerebellum [82]. Although these findings have shown that $\left[{ }^{18} \mathrm{~F}\right] \mathrm{FITM}$ is a prospective PET radiotracer for mGluR1, no further clinical PET studies have been reported in the literature. It is reported that $\left[{ }^{18} \mathrm{~F}\right]$ FITM could be prepared in poor radiochemical yields (14 $\pm 3 \%$ ), probably due to using the 4-nitrobenzamide precursor [80]. It is suggested that optimized methods for radiosynthesis of $\left[{ }^{18} \mathrm{~F}\right] \mathrm{FITM}$ should be developed. $N$-[4-[6-(Isopropylamino)pyrimidin-4-yl]1,3-thiazol-2-yl]-4-methoxy- $N$-methylbenzamide (ITMM, Figure 7) has been reported to be a highly potent and selective PET probe for mGluR1, with a $K_{i}$ value of $12.6 \mathrm{nM}$ (rat brain homogenate) and a $\log D$ value of 2.57. In vitro binding of $\left[{ }^{11} \mathrm{C}\right]$ ITMM was consistent with mGluR1 distribution, with high specific binding in mGluR1-rich regions. A PET study in rats found that $\left[{ }^{11} \mathrm{C}\right]$ ITMM displayed high brain uptake, with the highest uptake (in the cerebellum) being over 3.0 of the SUV (standardized uptake value). The in vivo distribution of $\left[{ }^{11} \mathrm{C}\right]$ ITMM was consistent with the in vitro data. The heterogeneous localization of $\left[{ }^{11} \mathrm{C}\right]$ ITMM was abolished by treatment with nonradioactive ITMM and an mGluR1selective ligand. In addition, a PET study of $\left[{ }^{11} \mathrm{C}\right]$ ITMM in the mGluR1 knockout mouse demonstrated quite low uptake and homogeneous distribution of radioactivity in the brain (Figure 8) [83]. Furthermore, $\left[{ }^{11} \mathrm{C}\right]$ ITMM showed reduced accumulation in the ischemic brain and treatment with the neuroprotective agent, minocycline, which may inhibit mGluR1 activation, abolished this decrease of mGluR1 in the brain [84]. Because $\left[{ }^{11} \mathrm{C}\right] \mathrm{ITMM}$ has been demonstrated to be a promising PET tracer for mGluR1, the first human PET studies have been performed. $\left[{ }^{11} \mathrm{C}\right]$ ITMM uptake increased gradually in the cerebellar cortex and $V_{T}$ in this brain region was 2.61, while $V_{T}$ was 0.53 in the mGluR1-poor pons. The rank order of $\left[{ }^{11} \mathrm{C}\right] \mathrm{ITMM}$ uptake was consistent with mGluR1 expression levels in the human brain (Figure 9). Because $\left[{ }^{11} \mathrm{C}\right] \mathrm{ITMM}$ showed relatively low uptake in the brain regions with a modest expression of mGluR1, such as the thalamus, hippocampus, and cerebral cortex, the $\left[{ }^{11} \mathrm{C}\right]$ ITMM signal in regions outside the cerebellum could be difficult to assess and this would make it hard to examine localization changes in these regions [85]. Nevertheless, $\left[{ }^{11} \mathrm{C}\right] \mathrm{ITMM}$ could be used to evaluate alterations in cerebellar mGluR1 under pathological conditions. Further clinical studies may be needed to assess the usefulness of $\left[{ }^{11} \mathrm{C}\right] \mathrm{ITMM}$ as a PET ligand for quantification of mGluR1.

$N$-[4-[6-(Isopropylamino)pyrimidin-4-yl]-1,3-thiazol-2yl]-N-methyl-4- ${ }^{11} \mathrm{C}$-methylbenzamide $\left(\left[{ }^{11} \mathrm{C}\right] \mathrm{ITDM}\right.$, Figure 7$)$, an analog of ITMM, also has high affinity for mGluR1 $\left(K_{i}\right.$ $=13.6 \mathrm{nM})$ and moderate lipophilicity $(\log D=1.74)$. PET studies of $\left[{ }^{11} \mathrm{C}\right]$ ITDM in the monkey brain showed localization consistent with known mGluR1 expression, fast kinetics, and a very low level of binding in the mGluR1-poor pons [86]. After detailed kinetic studies, $\left[{ }^{11} \mathrm{C}\right]$ ITDM was considered superior to $\left[{ }^{11} \mathrm{C}\right] \mathrm{ITMM}$ because of its higher regional $V_{T}$ values in the monkey brain [87]. Global reduction of $\left[{ }^{11} \mathrm{C}\right]$ ITDM binding was observed in the mGluR1-expressing brain regions of the R6/2 mouse model of Huntington's disease. The change in the radioactive signal correlated with the expression of mGluR1 in the brains of these R6/2 mice [88]. Thus, $\left[{ }^{11} \mathrm{C}\right] \mathrm{ITDM}$ has been confirmed as a promising PET ligand for monitoring changes in mGluR1 availability in the brain. To our knowledge, clinical PET studies with $\left[{ }^{11} \mathrm{C}\right]$ ITDM have not yet been published. $\left[{ }^{18} \mathrm{~F}\right] 4$-Fluoro- $N$ methyl- $N$-(4-(6-(methylamino)pyrimidin-4-yl)thiazol-2-yl) benzamide $\left(\left[{ }^{18}\right.\right.$ F]FIMX, Figure 7$)$ has been shown to have a high affinity for mGluR1 $\left(\mathrm{IC}_{50}=1.8 \mathrm{nM}\right)$ with high 
selectivity against a wide range of other human receptors $[79,89]$. $\left[{ }^{18}\right.$ F]FIMX was successfully synthesized by the radiofluorination of the diaryliodonium salts precursor. FIMX has moderate lipophilicity, with a $\log D$ value of 2.25. PET studies of $\left[{ }^{18}\right.$ F]FIMX in rhesus monkey demonstrated high $\mathrm{BBB}$ permeability and maximal uptake in the mGluR1-rich cerebellum (SUV $=5.3$ at $12 \mathrm{~min}$ ). The distribution of radioactivity in the brain matched mGluR1 expression, and accumulation was abolished by treatment with nonradioactive FIMX or the mGluR1-selective ligand JNJ-1625968553 (3 mg/kg, resp.). In contrast, an mGluR5selective ligand (MTEP) did not affect $\left[{ }^{18} \mathrm{~F}\right]$ FIMX binding in the monkey brain [89]. Apparently, $\left[{ }^{18}\right.$ F]FIMX is a prospective PET radioligand for imaging of mGluR1. Recently, an initial clinical PET imaging study using ${ }^{18} \mathrm{~F}$ FIMX was performed. The mGluR1-rich cerebellum had the highest uptake (SUV; 1.8 at $120 \mathrm{~min}$ ), whereas mGluR1-poor regions ranged from SUV values of $0.3-1$ at $120 \mathrm{~min}$ [90]. PET imaging of patients with a range of CNS disorders using $\left[{ }^{18}\right.$ F]FITM, $\left[{ }^{11} \mathrm{C}\right]$ ITMM, $\left[{ }^{11} \mathrm{C}\right]$ ITDM, and $\left[{ }^{18} \mathrm{~F}\right]$ FIMX could help to elucidate the relationship between these disorders and mGluR1.

3.1.3. Development of Imaging Probes for mGluR5. Several diaryl alkyne derivatives have been reported as high-affinity, selective mGluR5 antagonists that could be used as in vivo imaging probes. 3-Fluoro-5-(2-pyridinylethynyl) benzonitrile (FPEB, Figure 10) has been reported to have an excellent affinity for mGluR5, with a $K_{i}$ value of $0.2 \mathrm{nM}$ (rat brain cortex) and a moderate $\log P$ value of 2.8. Autoradiography of rhesus monkey brain demonstrated high accumulation in mGluR5-rich regions, such as the cortex, caudate, putamen, amygdala, hippocampus, and most thalamic nuclei, and a low signal in the mGluR5-poor cerebellar layers. In addition, the heterogeneous binding of $\left[{ }^{18} \mathrm{~F}\right] \mathrm{FPEB}$ was abolished in the presence of the mGluR5-selective ligand, MPEP, indicating that the radiotracer bound specifically to mGluR5 in vitro [91]. PET studies of $\left[{ }^{18} \mathrm{~F}\right]$ FPEB in rhesus monkey and rat showed similar localization to mGluR5 and displacement by mGluR5 ligands (Figure 11) [91, 92]. Building on these promising preclinical studies of $\left[{ }^{18} \mathrm{~F}\right] \mathrm{FPEB}$, an initial clinical PET study was performed to assess the usefulness of this radiotracer for PET imaging of mGluR5. The regional brain distribution of $\left[{ }^{18} \mathrm{~F}\right] \mathrm{FPEB}$ in the healthy adult brain matched the known expression of mGluR5 and showed high reproducibility, suggesting that $\left[{ }^{18} \mathrm{~F}\right] \mathrm{FPEB}$ is a suitable PET radioligand for mGluR5 in the human brain [93].

3-(6-Methyl-pyridin-2-ylethynyl)-cyclohex-2-enoneO- ${ }^{11} \mathrm{C}$-methyl-oxime $\left(\left[{ }^{11} \mathrm{C}\right]\right.$-ABP688, Figure 10$)$ has been reported as a highly selective and potent radiotracer for the mGluR5 allosteric site, with a $K_{d}$ value of $1.7 \mathrm{nM}$ in rat brain homogenates. Ex vivo autoradiography of $\left[{ }^{11} \mathrm{C}\right] \mathrm{ABP} 688$ demonstrated high accumulation of this radiotracer in mGluR5-rich brain regions, such as the cingulate cortex, striatum, and hippocampus. Treatment with M-MPEP $(1 \mathrm{mg} / \mathrm{kg})$, an mGluR5-selective antagonist, abolished the heterogeneous localization of $\left[{ }^{11} \mathrm{C}\right] \mathrm{ABP} 688$. PET studies using $\left[{ }^{11} \mathrm{C}\right]$ ABP688 in normal rats demonstrated a similar distribution to that observed in ex vivo experiments (Figure 12). In addition, accumulation of this radiotracer was almost homogeneous in mGluR5-knockout mice, indicating that $\left[{ }^{11} \mathrm{C}\right] \mathrm{ABP} 688$ was highly specific for mGluR5 in the living brain [94]. A clinical PET study of $\left[{ }^{11} \mathrm{C}\right] \mathrm{ABP} 688$ in human brain demonstrated high accumulation in mGluR5rich brain regions but low levels in the mGluR5-poor regions, consistent with the results of rat PET studies. Its specific distribution volume in the brain regions ranged from 5.45 (anterior cingulate) to 1.91 (cerebellum), and the rank order of these values was consistent with the known mGluR5 density. These results suggested that $\left[{ }^{11} \mathrm{C}\right] \mathrm{ABP} 688$ could be used for PET quantification of mGluR5 in the human brain [95]. It has also been reported that $\left[{ }^{11} \mathrm{C}\right] \mathrm{ABP} 688$ can be used for monitoring mGluR5 drug occupancy. AZD2066, a highly potent mGluR5-selective ligand, dose-dependently displaced $\left[{ }^{11} \mathrm{C}\right] \mathrm{ABP} 688$ binding in the human brain (Figure 13). In this study, the dose of AZD2066 required to produce $50 \%$ mGluR5 occupancy was estimated to be $13.5 \mathrm{mg}$ [96]. On the other hand, there are two geometrical isomers of $\left[{ }^{11} \mathrm{C}\right] \mathrm{ABP} 688$ and the $E$-isomer has a much higher binding affinity for mGluR5 than the $Z$-isomer $\left(K_{d}=5.7 \mathrm{nM}\right.$ versus $140 \mathrm{nM})$. In a rat PET study of $\left[{ }^{11} \mathrm{C}\right] \mathrm{ABP} 688$, the $E$-isomer showed high brain uptake and distribution that was consistent with mGluR5 expression. In contrast, the $Z$-isomer showed low brain retention and homogeneous binding throughout the brain [97]. Although $\left[{ }^{11} \mathrm{C}\right] \mathrm{ABP} 688$ could be synthesized with an $E$-isomer to $Z$-isomer ratio of > $10: 1$ [94], it has been suggested that $E$ - $\left[{ }^{11} \mathrm{C}\right] \mathrm{ABP} 688$ should be used for reproducible imaging of mGlu5 receptors in clinical studies. 3-Fluoro-5-[2-[2-([ $\left[{ }^{18} \mathrm{~F}\right]$ fluoromethyl)thiazol4-yl]ethynyl]benzonitrile $\left(\left[{ }^{18} \mathrm{~F}\right] \mathrm{SP} 203\right.$, Figure 10) has been developed as a negative allosteric modulator with excellent affinity $(40 \mathrm{pM})$ for mGluR5. PET studies using $\left[{ }^{18} \mathrm{~F}\right] \mathrm{SP} 203$ demonstrated high uptake in mGluR5-rich regions and the signal was greatly diminished by treatment with the mGluR5selective ligand MPEP $(5 \mathrm{mg} / \mathrm{kg})$ [98]. One disadvantage of $\left[{ }^{18} \mathrm{~F}\right] \mathrm{SP} 203$ is the ease of its defluorination by glutathione $S$-transferase in the rat brain [99]. However, because primates have much lower levels of glutathione S-transferase [100], initial PET studies were conducted with $\left[{ }^{18} \mathrm{~F}\right] \mathrm{SP} 203$ in healthy human subjects. PET images showed high brain uptake of $\left[{ }^{18} \mathrm{~F}\right] \mathrm{SP} 203$ (Figure 14) with little defluorination and brain uptake could be calculated as $V_{T}$ in humans. $\left[{ }^{18} \mathrm{~F}\right]$ SP203 had high BBB permeability (\% SUV; 580) and the rank order of $V_{T}$ values in the brain regions was as follows: neocortex (20-26) > thalamus (15) $\fallingdotseq$ cerebellum (14), consistent with the levels of mGluR5 in the human brain [101]. Therefore, despite the issue of defluorination, ${ }^{18} \mathrm{~F}-\mathrm{SP} 203$ can be used for quantification of mGluR5 by PET.

3.1.4. mGluR5-Selective PET Imaging in Diseases. Cocaine exposure has been reported to reduce mGluR5 expression in the rodent brain [102]. Clinical PET studies were conducted with $\left[{ }^{11} \mathrm{C}\right] \mathrm{ABP} 688$ in cocaine-addicted participants, in comparison with healthy control subjects. $\left[{ }^{11} \mathrm{C}\right] \mathrm{ABP} 688$ binding in the striatum was reduced by approximately $20 \%$ 
<smiles>N#Cc1cc(F)cc(C#Cc2ccccn2)c1</smiles>

$\left[{ }^{18} \mathrm{~F}\right] \mathrm{FPEB}$<smiles>N#Cc1cc(F)cc(C#Cc2csc(C[18F])n2)c1</smiles>

$\left[{ }^{18} \mathrm{~F}\right] \mathrm{SP} 203$<smiles>CON=C1C=C(C#Cc2cccc(C)n2)CCC1</smiles>

(E)- $\left[{ }^{11} \mathrm{C}\right] \mathrm{ABP} 688$<smiles>CON=C1C=C(C#Cc2cccc(C)n2)CCC1</smiles>

(Z)- $\left[{ }^{11} \mathrm{C}\right] \mathrm{ABP} 688$

FIGURE 10: Chemical structure of imaging probes for mGluR5.

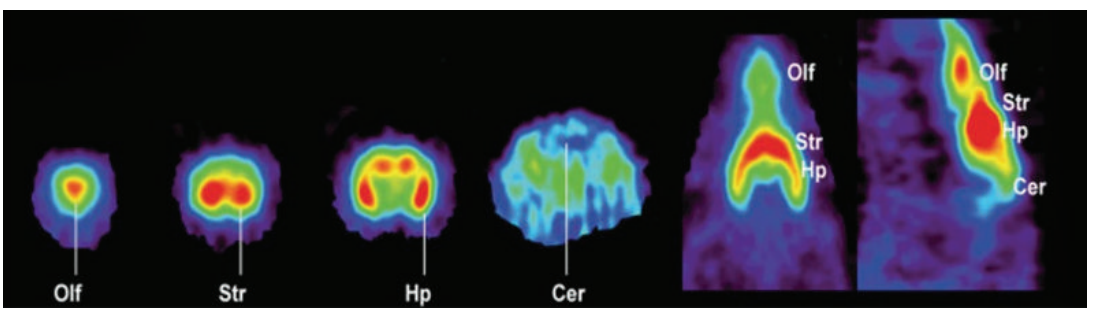

(a)

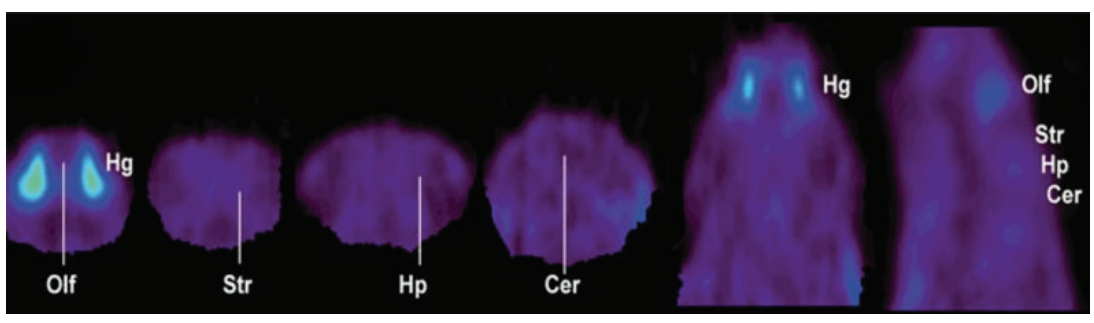

(b)

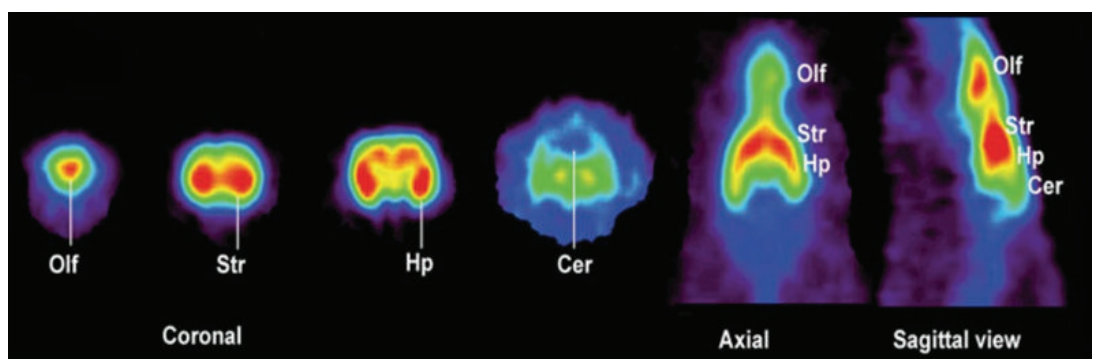

Min

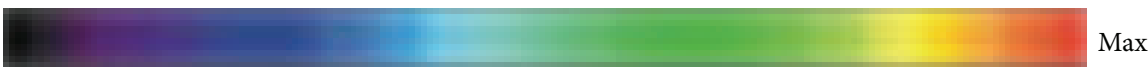

(c)

FIGURE 11: PET images of $\left[{ }^{18} \mathrm{~F}\right]$ FPEB (20-25 min) in rat brain without drug treatment (a), treatment of mGluR5-selective ligand MTEP treatment $(10 \mathrm{mg} / \mathrm{kg})(\mathrm{b})$, and treatment of mGluR1-selective YM-298198 (10 mg/kg) [92].

in cocaine-addicted participants [103]. Another clinical PET study with $\left[{ }^{11} \mathrm{C}\right] \mathrm{ABP} 688$ demonstrated that mGluR5 availability in cocaine-dependent subjects was inversely proportional to the duration of cocaine abstinence [104]. These studies indicated that distribution of mGluR5 was decreased in the striatum of the living brain in cocaine-abstinent individuals, information that could inform novel strategies for the control of cocaine addiction via mGluR5. Preclinical studies have demonstrated that mGluR5 antagonists potently reduced self-administration of nicotine $[105,106]$. In a PET study, a significant reduction in $\left[{ }^{11} \mathrm{C}\right] \mathrm{ABP} 688$ binding was observed in the gray matter of smokers (Figure 15), indicating that mGluR5 could be a potential target for the treatment of nicotine dependence [107]. mGluR5 have been suggested to be involved in the pathophysiology of epilepsy [108, 109]. PET studies using $\left[{ }^{11} \mathrm{C}\right] \mathrm{ABP} 688$ revealed lower levels of mGluR5 binding in the hippocampus and amygdala in rat models of chronic epilepsy, as compared to a control group. Therefore, PET imaging of mGluR5 in the temporal and spatial regions could detect dysregulated glutamatergic networks during epileptogenesis [110]. mGluR5 may also be linked to the pathophysiology of major depression [65]. Clinical PET studies using $\left[{ }^{11} \mathrm{C}\right] \mathrm{ABP} 688$ showed reduced mGluR5 binding in the cortical regions, thalamus, and hippocampus of patients 


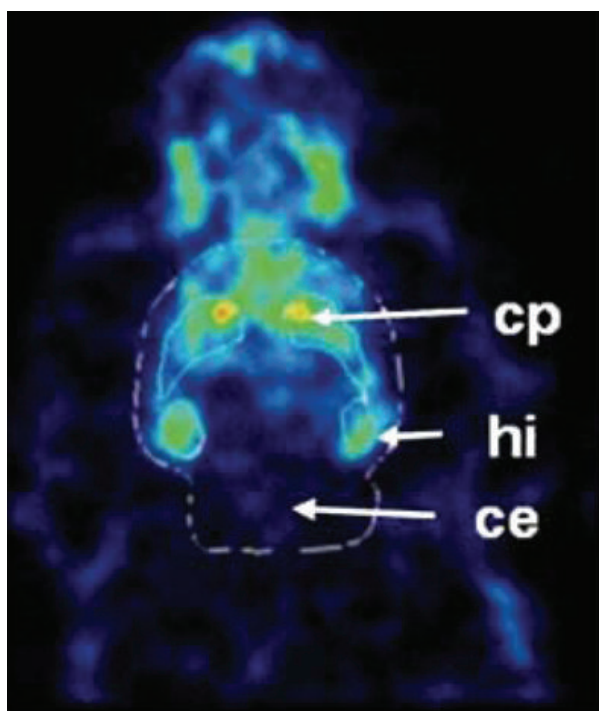

(a)

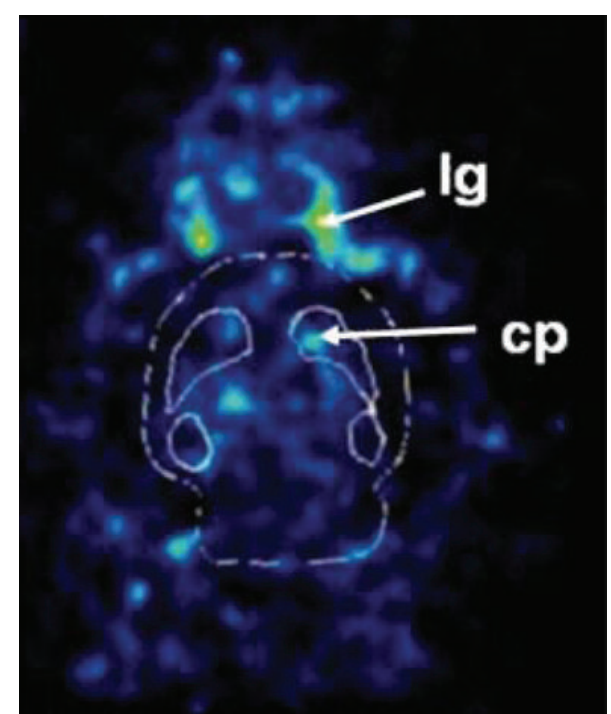

(b)

FIGURE 12: PET images of $\left[{ }^{11} \mathrm{C}\right] \mathrm{ABP} 688$ (0-30 min) in control rats (a) and an mGluR5-selective ligand M-MPEP (1.0 mg/kg) treated rat [94].

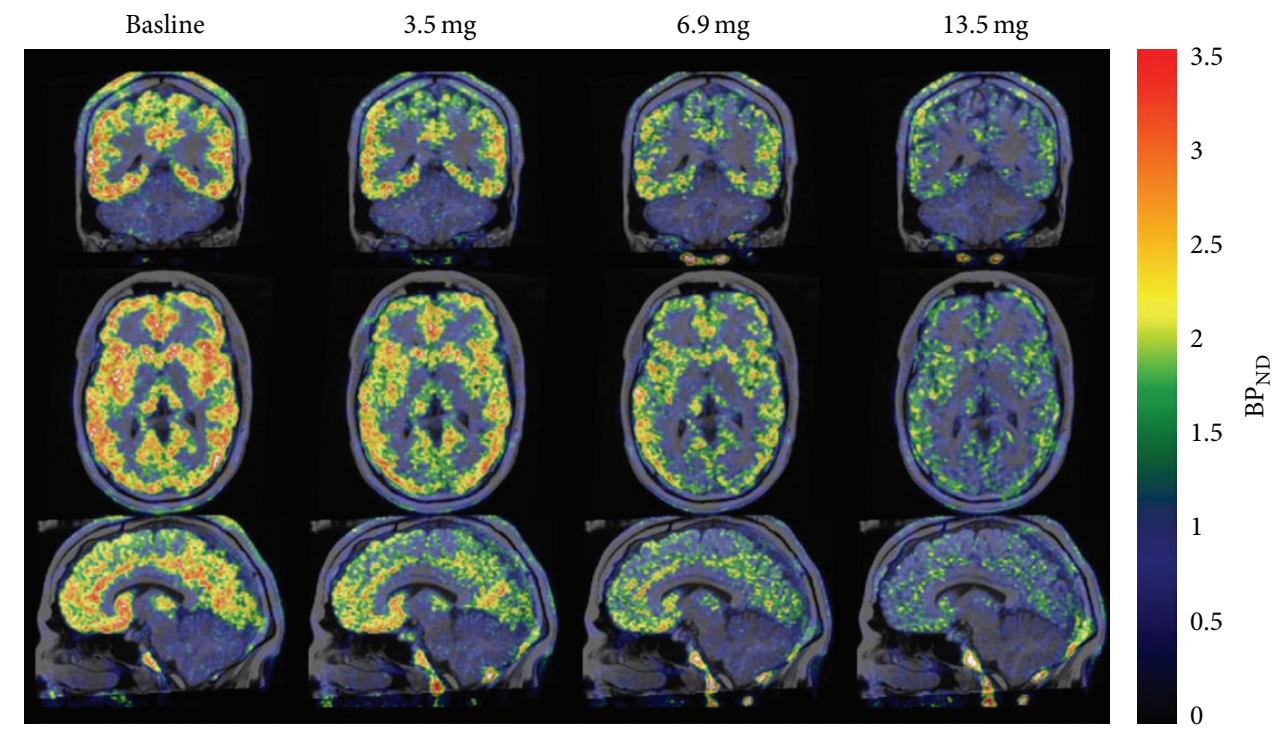

FIGURE 13: PET/MR images (0-63 min) showing the effect of AZD2066 on binding of $\left[{ }^{11} \mathrm{C}\right] \mathrm{ABP} 688$ [96].

with depression. Furthermore, mGluR5 availability in the hippocampus decreased with the increased severity of this disease, suggesting that changes in the availability of mGluR5 may provide a potential biomarker for the diagnosis of depression [111].

\subsection{Imaging Probes for Groups II and III mGluRs}

3.2.1. Physiology of Groups II and III mGluRs. Groups II (mGluR2 and mGluR3) and III (mGluR4, mGluR6, mGluR7, and mGluR8) mGluRs are primarily localized within presynaptic regions and involved in the inhibition of neurotransmitter release [70]. Groups II and III mGluRs are coupled to $G_{i} / G_{o}$ and downregulate cAMP levels via inhibition of adenylate cyclase. These events activate the MAPK and phosphatidylinositol 3-kinase (PI3) pathways, which regulate synaptic transmission. mGluR2 has been predominantly observed in the cerebellar cortex and olfactory bulb, while mGluR3 has been found widely throughout the brain. mGluR4 is predominantly expressed in the cerebellum. The expression of mGluR6 is restricted to the retina, whereas mGluR7 has a widespread distribution in the brain. mGluR8 is mainly expressed in the olfactory bulbs, olfactory nucleus, piriform cortex, entorhinal cortex, and medulla oblongata [71]. Agonists of group II mGluRs may be useful in the treatment of anxiety disorders and schizophrenia [73]. mGluR2/3 are involved in the pathophysiology of schizophrenia [112]. Group III mGluRs are attractive targets for the treatment 


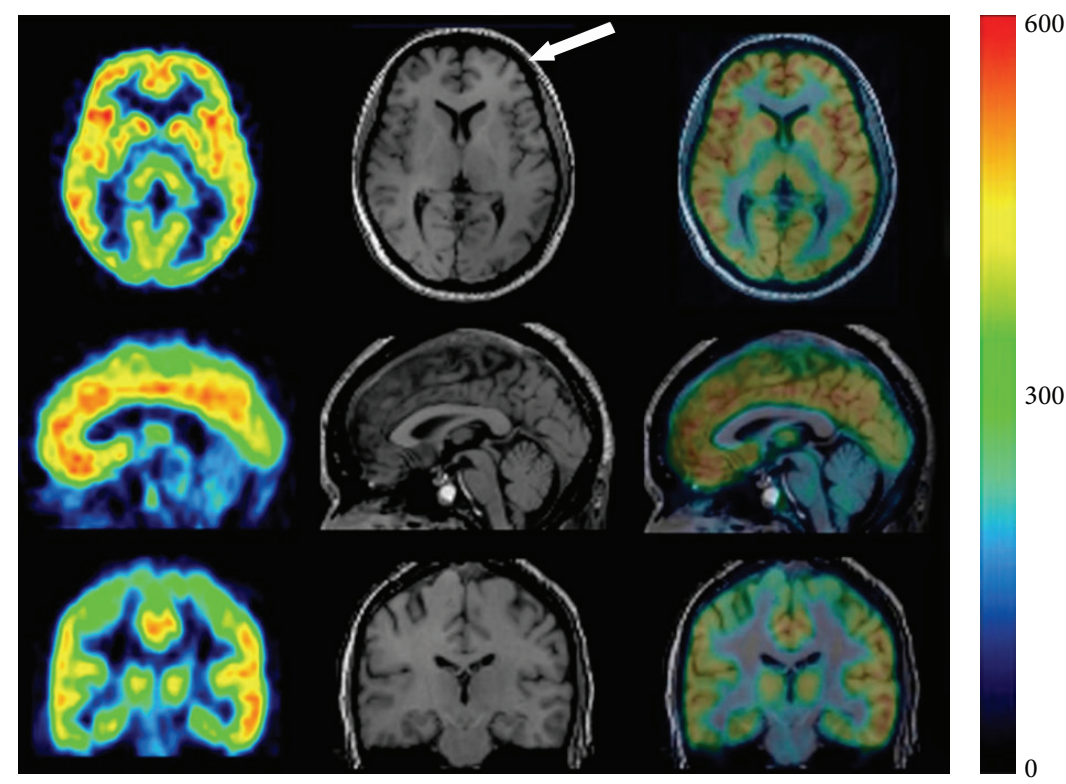

Figure 14: PET/MR images of $\left[{ }^{18}\right.$ F]SP203 (60-180 min) in healthy subject. Arrow points to subcutaneous fat [101].

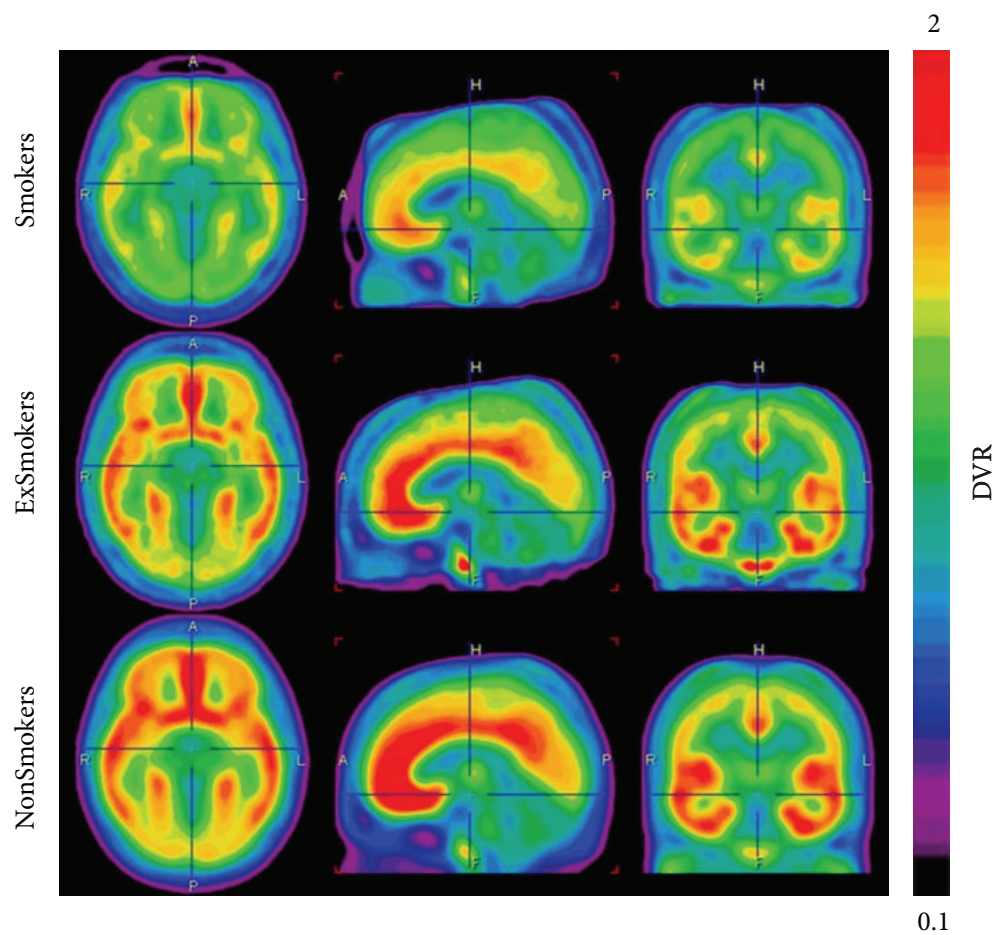

FigURE 15: PET Images of the average mGluR5 DVR $(0-40 \mathrm{~min})$ using $\left[{ }^{11} \mathrm{C}\right] \mathrm{ABP} 688$ in the three diagnostic groups $(n=14)[107]$.<smiles>COc1c(F)ccc(F)c1C1CCN(c2ccn3c(CC4CC4)nnc3c2Cl)CC1</smiles>

$\left[{ }^{11} \mathrm{C}\right] J \mathrm{~N} J 42491293$<smiles>COc1cc(NC(=O)c2ccccn2)ccc1Cl</smiles>

$\left[{ }^{11} \mathrm{C}\right] \mathrm{ML} 128$<smiles>COc1ccc(-c2cc3onc(-c4ccncc4)c3c(=O)n2C)cc1</smiles>

$\left[{ }^{11} \mathrm{C}\right]$ MMPIP

FIGURE 16: Chemical structure of imaging probes for groups II and III mGluRs. 
of Parkinson's disease [113]. mGluR8 is implicated in drug addiction mechanisms [114].

3.2.2. Development of Imaging Probes for Group II $m$ GluRs. 8-Chloro-3-(cyclopropylmethyl)-7-[4-(3,6-difluoro-2methoxyphenyl)-1-piperidinyl]-1,2,4-triazolo[4,3-a]pyridine $\left(\left[{ }^{11} \mathrm{C}\right] J N\right) 42491293$, Figure 16) has been reported to act as a potent positive allosteric modulator for mGluR2, with an $\mathrm{IC}_{50}$ of $9.2 \mathrm{nM}$ for the human mGluR2 and a high selectivity against other mGluRs. In vivo biodistribution and PET studies in rats demonstrated a high brain uptake of $\left[{ }^{11} \mathrm{C}\right] J \mathrm{~N} J 42491293$, with a signal matching the known distribution of mGluR2 that was displaced by JNJ42153605, a selective mGluR2 agonist, in all brain regions. $\left.\left[{ }^{11} \mathrm{C}\right]\right] \mathrm{NJ} 42491293$ may be a promising PET radiotracer for the mGluR2 allosteric binding site [115]. PET studies using $\left[{ }^{11} \mathrm{C}\right] J N J 42491293$ in healthy male subjects demonstrated high brain uptake, which reached a maximum $30 \mathrm{~min}$ after treatment. Considerable $\left[{ }^{11} \mathrm{C}\right] \mathrm{JNJ} 42491293$ distribution was observed in the striatum and cerebellum, consistent with known mGluR2 expression patterns. $\left[{ }^{11} \mathrm{C}\right]$ JNJ42491293 has been demonstrated to be a prospective PET radioligand for monitoring mGluR2 availability in the human brain [116].

\subsubsection{Development of Imaging Probes for Group III mGluRs.} $\mathrm{N}$-(Chloro-3-methoxyphenyl)-2-picolinamide (ML128, Figure 16) has been developed as a positive allosteric modulator of mGluR4 with an $\mathrm{EC}_{50}$ of $110 \mathrm{nM}$ for rat mGluR4 [117]. $\left[{ }^{11} \mathrm{C}\right] \mathrm{ML} 128$ has been synthesized and evaluated as a PET imaging probe for mGluR4. In rat PET studies, $\left[{ }^{11} \mathrm{C}\right]$ ML128 showed high BBB penetration and localization to the hippocampus, striatum, thalamus, olfactory bulb, and cerebellum, consistent with the distribution of mGluR4. Treatment with an mGluR4 modulator led to some reduction $(22-28 \%)$ in $\left[{ }^{11} \mathrm{C}\right]$ ML128 binding in the brain. Because this radiotracer exhibited fast washout within $20 \mathrm{~min}$ throughout the brain, structural modification will be necessary to provide useful in vivo imaging probes for mGluR4 [118]. MMPIP (6-(4-methoxyphenyl-5-methyl-3-pyridin-4ylisozazolo[4,5-c]pyridine-4(5H)-one)) is an allosteric mGluR7 antagonist with a $K_{b}$ of $30 \mathrm{nM}[119]$. $\left[{ }^{11} \mathrm{C}\right] \mathrm{MMPIP}$ (Figure 16) has been synthesized and evaluated as a PET radioligand for mGluR7. Although $\left[{ }^{11} \mathrm{C}\right] \mathrm{MMPIP}$ showed specific in vitro binding in rat brain, PET studies of this radioligand in rats demonstrated low brain uptake and no specific localization to sites of mGluR7 expression.

\section{Conclusion and Perspectives}

Despite considerable efforts, no radioligands are currently available for human in vivo PET or SPECT imaging of NMDARs. There are three potential target sites for imaging agents; the channel blocker site, the glycine site, and the NR2B negative modulator site. $\left[{ }^{123 / 125} \mathrm{I}\right.$ ]CNS 1261 is a potential imaging agent acting at the channel blocker site. However, this ligand requires further research to address its input function alteration in pathological state metabolic instability and potentially nonspecific binding. There are no radioligands for glycine site or the NR2B negative modulator site that have shown enough promise to warrant clinical studies. Although several ligands showed localization patterns consistent with NMDAR expression and high specific binding in vitro, they did not show these characteristics in vivo. This discrepancy might be due to the dynamic properties of NMDARs. It is known that NMDAR structure is altered by binding of endogenous or exogenous ligands [1]. Importantly, the number of NMDARs on the cell surface is changed by tyrosine phosphorylation, cysteine palmitoylation of the NMDAR Cterminus, and by an alteration in subunit composition [120122]. In addition to developing novel classes of imaging probes for NMDARs, further in vivo imaging studies of NMDAR models should be performed to clarify the discrepancies between the findings of in vitro and in vivo studies.

In contrast to the situation with NMDARs, several promising PET probes for mGluRs have been developed successfully. PET radioligands for mGluR1, such as $\left[{ }^{18} \mathrm{~F}\right] \mathrm{FITM}$, $\left[{ }^{11} \mathrm{C}\right]$ ITMM, $\left[{ }^{11} \mathrm{C}\right]$ ITDM, and $\left[{ }^{18} \mathrm{~F}\right]$ FIMX, have proved useful in clinical PET studies. PET imaging studies of mGluR5 with selective radiotracers $\left(\left[{ }^{18} \mathrm{~F}\right] \mathrm{FPEB},\left[{ }^{18} \mathrm{~F}\right] \mathrm{SP} 203\right.$, and $\left.\left[{ }^{11} \mathrm{C}\right] \mathrm{ABP} 688\right)$ have enabled evaluation of mGluR5 availability in relevant disease states. $\left[{ }^{11} \mathrm{C}\right] J \mathrm{NJ} 42491293$ has been developed as a clinically useful prospective PET probe for mGluR2. Further PET investigations of patients with various mGluR-related diseases could make it possible to resolve the roles of mGluRs in these disorders, monitor mGluR activity, and quantify mGluR occupancy by therapeutic agents. As no clinically useful PET ligands for group III mGluRs have yet been identified, continued efforts should be made to develop high-affinity and selective ligands for these receptors.

\section{Conflict of Interests}

The authors declare that there is no conflict of interests regarding the publishing of this paper.

\section{References}

[1] S. F. Traynelis, L. P. Wollmuth, C. J. McBain et al., "Glutamate receptor ion channels: Structure, regulation, and function," Pharmacological Reviews, vol. 62, no. 3, pp. 405-496, 2010.

[2] C. M. Niswender and P. J. Conn, "Metabotropic glutamate receptors: physiology, pharmacology, and disease," Annual Review of Pharmacology and Toxicology, vol. 50, pp. 295-322, 2010.

[3] D. Bowie, "Ionotropic glutamate receptors \& CNS disorders," CNS and Neurological Disorders-Drug Targets, vol. 7, no. 2, pp. 129-143, 2008.

[4] A. Lau and M. Tymianski, "Glutamate receptors, neurotoxicity and neurodegeneration," Pflugers Archiv European Journal of Physiology, vol. 460, no. 2, pp. 525-542, 2010.

[5] G. Riedel, B. Platt, and J. Micheau, "Glutamate receptor function in learning and memory," Behavioural Brain Research, vol. 140, no. 1-2, pp. 1-47, 2003.

[6] C. G. Lau and R. S. Zukin, "NMDA receptor trafficking in synaptic plasticity and neuropsychiatric disorders," Nature Reviews Neuroscience, vol. 8, no. 6, pp. 413-426, 2007.

[7] J. A. Kemp and R. M. McKernan, "NMDA receptor pathways as drug targets," Nature Neuroscience, vol. 5, pp. 1039-1042, 2002. 
[8] L. V. Kalia, S. K. Kalia, and M. W. Salter, "NMDA receptors in clinical neurology: excitatory times ahead," The Lancet Neurology, vol. 7, no. 8, pp. 742-755, 2008.

[9] R. Dingledine, K. Borges, D. Bowie, and S. F. Traynelis, "The glutamate receptor ion channels," Pharmacological Reviews, vol. 51, no. 1, pp. 7-61, 1999.

[10] B. Laube, J. Kuhse, and H. Betz, "Evidence for a tetrameric structure of recombinant NMDA receptors," Journal of Neuroscience, vol. 18, no. 8, pp. 2954-2961, 1998.

[11] H. Furukawa, S. K. Singh, R. Mancusso, and E. Gouaux, "Subunit arrangement and function in NMDA receptors," Nature, vol. 438, no. 7065, pp. 185-192, 2005.

[12] M. H. Ulbrich and E. Y. Isacoff, "Rules of engagement for NMDA receptor subunits," Proceedings of the National Academy of Sciences of the United States of America, vol. 105, no. 37, pp. 14163-14168, 2008.

[13] P. Paoletti and J. Neyton, "NMDA receptor subunits: function and pharmacology," Current Opinion in Pharmacology, vol. 7, no. 1, pp. 39-47, 2007.

[14] C.-M. Low and K. S.-L. Wee, "New insights into the not-so-new NR3 subunits of N-methyl-D-aspartate receptor: localization, structure, and function," Molecular Pharmacology, vol. 78, no. 1, pp. 1-11, 2010.

[15] H. Furukawa and E. Gouaux, "Mechanisms of activation, inhibition and specificity: crystal structures of the NMDA receptor NR1 ligand-binding core," EMBO Journal, vol. 22, no. 12, pp. 2873-2885, 2003.

[16] Y. Yao, C. B. Harrison, P. L. Freddolino, K. Schulten, and M. L. Mayer, "Molecular mechanism of ligand recognition by NR3 subtype glutamate receptors," The EMBO Journal, vol. 27, no. 15, pp. 2158-2170, 2008.

[17] L. Mony, J. N. C. Kew, M. J. Gunthorpe, and P. Paoletti, "Allosteric modulators of NR2B-containing NMDA receptors: molecular mechanisms and therapeutic potential," British Journal of Pharmacology, vol. 157, no. 8, pp. 1301-1317, 2009.

[18] N. A. Anis, S. C. Berry, N. R. Burton, and D. Lodge, "The dissociative anaesthetics, ketamine and phencyclidine, selectively reduce excitation of central mammalian neurones by $\mathrm{N}$-methylaspartate," British Journal of Pharmacology, vol. 79, no. 2, pp. 565-575, 1983.

[19] A. C. Foster and E. H. F. Wong, "The novel anticonvulsant MK801 binds to the activated state of the N-methyl-D-aspartate receptor in rat brain," British Journal of Pharmacology, vol. 91, no. 2, pp. 403-409, 1987.

[20] E. Karakas, N. Simorowski, and H. Furukawa, "Subunit arrangement and phenylethanolamine binding in GluN1/GluN2B NMDA receptors," Nature, vol. 475, no. 7355, pp. 249-253, 2011.

[21] J. N. C. Kew and J. A. Kemp, "Ionotropic and metabotropic glutamate receptor structure and pharmacology," Psychopharmacology, vol. 179, no. 1, pp. 4-29, 2005.

[22] P. Loo, A. Braunwalder, J. Lehmann, and M. Williams, "Radioligand binding to central phencyclidine recognition sites is dependent on excitatory amino acid receptor agonists," European Journal of Pharmacology, vol. 123, no. 3, pp. 467-468, 1986.

[23] E. H. F. Wong, A. R. Knight, and G. N. Woodruff, “ $\left[{ }^{3} \mathrm{H}\right] \mathrm{MK}-$ 801 labels a site on the $\mathrm{N}$-methyl-D-aspartate receptor channel complex in rat brain membranes," Journal of Neurochemistry, vol. 50, no. 1, pp. 274-281, 1988.

[24] K. Orita, S. Sasaki, M. Maeda et al., "Synthesis and evaluation of 1-1-[5- $\left(2^{\prime}-\left[{ }^{18} \mathrm{~F}\right]\right.$ Fluoroethyl $)$-2-thienyl]-cyclohexylpiperidine as a potential in vivo radioligand for the NMDA receptor-Channel complex," Nuclear Medicine and Biology, vol. 20, no. 7, pp. 865873, 1993.

[25] S. Sihver, W. Sihver, Y. Andersson et al., "In vitro and in vivo characterization of (+)-3-[ $\left[{ }^{11} \mathrm{C}\right]$ cyano-dizocilpine," Journal of Neural Transmission, vol. 105, no. 2-3, pp. 117-131, 1998.

[26] J. Owens, A. A. Tebbutt, A. L. McGregor et al., "Synthesis and binding characteristics of $\mathrm{N}-(1-$ naphthyl $)-\mathrm{N}^{\prime}-\left(3-\left[{ }^{125} \mathrm{I}\right]-\right.$ iodophenyl)- $\mathrm{N}^{\prime}$-methylguanidine ([ $\left.\left.{ }^{125} \mathrm{I}\right]-\mathrm{CNS} 1261\right)$ : a potential SPECT agent for imaging NMDA receptor activation," Nuclear Medicine and Biology, vol. 27, no. 6, pp. 557-564, 2000.

[27] K. Erlandsson, R. A. Bressan, R. S. Mulligan et al., "Kinetic modelling of $\left[{ }^{123} \mathrm{I}\right] \mathrm{CNS} 1261$ - a potential SPET tracer for the NMDA receptor," Nuclear Medicine and Biology, vol. 30, no. 4, pp. 441-454, 2003.

[28] R. A. Bressan, K. Erlandsson, R. S. Mulligan et al., "A bolus/infusion paradigm for the novel NMDA receptor SPET tracer $\left[{ }^{123} \mathrm{I}\right] \mathrm{CNS}$ 1261," Nuclear Medicine and Biology, vol. 31, no. 2, pp. 155-164, 2004.

[29] J. T. Kantrowitz and D. C. Javitt, "N-methyl-d-aspartate (NMDA) receptor dysfunction or dysregulation: the final common pathway on the road to schizophrenia?" Brain Research Bulletin, vol. 83, no. 3-4, pp. 108-121, 2010.

[30] C. H. Lin, H. Y. Lane, and G. E. Tsai, "Glutamate signaling in the pathophysiology and therapy of schizophrenia," Pharmacology Biochemistry and Behavior, vol. 100, no. 4, pp. 665-677, 2012.

[31] L. S. Pilowsky, R. A. Bressan, J. M. Stone et al., "First in vivo evidence of an NMDA receptor deficit in medication-free schizophrenic patients," Molecular Psychiatry, vol. 11, no. 2, pp. 118-119, 2006.

[32] R. A. Bressan, K. Erlandsson, J. M. Stone et al., "Impact of schizophrenia and chronic antipsychotic treatment on $\left.{ }^{[23} \mathrm{I}\right] \mathrm{CNS}-1261$ binding to $N$-methyl-D-aspartate receptors in vivo," Biological Psychiatry, vol. 58, no. 1, pp. 41-46, 2005.

[33] R. N. Waterhouse, M. Slifstein, F. Dumont et al., "In vivo evaluation of $\left[{ }^{11} \mathrm{C}\right] \mathrm{N}$-(2-chloro-5-thiomethylphenyl)- $N^{\prime}$ (3-methoxy-phenyl)- $N^{\prime}$-methylguanidine $\left(\left[{ }^{11} \mathrm{C}\right] \mathrm{GMOM}\right)$ as a potential PET radiotracer for the PCP/NMDA receptor," Nuclear Medicine and Biology, vol. 31, no. 7, pp. 939-948, 2004.

[34] A. Biegon, A. Gibbs, M. Alvarado, M. Ono, and S. Taylor, "In vitro and in vivo characterization of $\left[{ }^{3} \mathrm{H}\right] \mathrm{CNS}-5161-\mathrm{a}$ usedependent ligand for the $N$-methyl-D-aspartate receptor in rat brain," Synapse, vol. 61, no. 8, pp. 577-586, 2007.

[35] M. C. Asselin, A. Hammers, D. Turton, S. Osman, M. Koepp, and D. Brooks, "Initial kinetic analysis of the in vivo binding of the putative NMDA receptor ligand $\left[{ }^{11} \mathrm{C}\right] \mathrm{CNS} 5161$ in humans," Neuroimage, vol. 22, p. T137, 2004.

[36] E. G. Robins, Y. Zhao, I. Khan, A. Wilson, S. K. Luthra, and E. Årstad, "Synthesis and in vitro evaluation of ${ }^{18} \mathrm{~F}$-labelled Sfluoroalkyl diarylguanidines: novel high-affinity NMDA receptor antagonists for imaging with PET,' Bioorganic and Medicinal Chemistry Letters, vol. 20, no. 5, pp. 1749-1751, 2010.

[37] C. J. McGinnity, A. Hammers, D. A. R. Barros et al., "Initial evaluation of ${ }^{18}$ F-GE-179, a putative PEt tracer for activated $N$ methyl D-aspartate receptors," Journal of Nuclear Medicine, vol. 55, no. 3, pp. 423-430, 2014.

[38] W. Danysz and C. G. Parsons, "Glycine and N-methyl-Daspartate receptors: physiological significance and possible therapeutic applications," Pharmacological Reviews, vol. 50, no. 4, pp. 597-664, 1998.

[39] R. N. Waterhouse, A. Sultana, and M. Laruelle, "In vivo evaluation of $\left[{ }^{11} \mathrm{C}\right]-3-[2-[(3-$ methoxyphenylamino $)$ carbonyl $]-$ ethenyl $]-4,6$ - dichloroindole-2-carboxylic acid $\left(\left[{ }^{11} \mathrm{C}\right] 3 \mathrm{MPICA}\right)$ 
as a PET radiotracer for the glycine site of the NMDA ion channel," Nuclear Medicine and Biology, vol. 29, no. 8, pp. 791794, 2002.

[40] M. Piel, R. Schirrmacher, S. Höhnemann et al., "Synthesis and evaluation of 5, 7-dichloro-4-(3-\{4-[4-(2-[ $\left.{ }^{18} \mathrm{~F}\right]$ fluoroethyl)piperazin-1-yl]-phenyl\}-ureido)-1, 2, 3, 4-tetrahydroquinoline2-carboxylic acid as a potential NMDA ligand to study glutamatergic neurotransmission in vivo," Journal of Labelled Compounds and Radiopharmaceuticals, vol. 46, pp. 645-659, 2003.

[41] J. J. Kulagowski, R. Baker, N. R. Curtis et al., " 3 ' -(Arylmethyl)and $\quad 3^{\prime}$-(aryloxy)-3-phenyl-4-hydroxyquinolin-2(1H)-ones: orally active antagonists of the glycine site on the NMDA receptor," Journal of Medicinal Chemistry, vol. 37, no. 10, pp. 1402-1405, 1994.

[42] M. Rowley, J. J. Kulagowski, A. P. Watt et al., "Effect of plasma protein binding-on in vivo activity and brain penetration of glycine/NMDA receptor antagonists," Journal of Medicinal Chemistry, vol. 40, no. 25, pp. 4053-4068, 1997.

[43] T. Haradahira, M.-R. Zhang, J. Maeda et al., "A strategy for increasing the brain uptake of a radioligand in animals: use of a drug that inhibits plasma protein binding," Nuclear Medicine and Biology, vol. 27, no. 4, pp. 357-360, 2000.

[44] T. Haradahira, M.-R. Zhang, J. Maeda et al., "A prodrug of NMDA/Glycine site antagonist, L-703,717, with improved BBB permeability: 4-acetoxy derivative and its positron-emitter labeled analog," Chemical and Pharmaceutical Bulletin, vol. 49, no. 2, pp. 147-150, 2001.

[45] R. Matsumoto, T. Haradahira, H. Ito et al., "Measurement of glycine binding site of $N$-methyl-D-asparate receptors in living human brain using 4-acetoxy derivative of L-703,717, 4-acetoxy-7-chloro- 3-[3-(4-[ $\left.{ }^{11} \mathrm{C}\right]$ methoxybenzyl) phenyl]$2(1 \mathrm{H})$-quinolone (AcL703) with positron emission tomography," Synapse, vol. 61, no. 10, pp. 795-800, 2007.

[46] T. Fuchigami, T. Haradahira, N. Fujimoto et al., "Difference in brain distributions of carbon 11-labeled 4-hydroxy-2(1H)quinolones as PET radioligands for the glycine-binding site of the NMDA ion channel," Nuclear Medicine and Biology, vol. 35, no. 2, pp. 203-212, 2008.

[47] T. Fuchigami, T. Haradahira, N. Fujimoto et al., "Development of $N$ - $\left[{ }^{11} \mathrm{C}\right]$ methylamino 4-hydroxy-2(1H)-quinolone derivatives as PET radioligands for the glycine-binding site of NMDA receptors," Bioorganic and Medicinal Chemistry, vol. 17, no. 15, pp. 5665-5675, 2009.

[48] A. Hashimoto, T. Nishikawa, T. Oka, and K. Takahashi, "Endogenous D-serine in rat brain: $N$-methyl-D-aspartate receptor-related distribution and aging," Journal of Neurochemistry, vol. 60, no. 2, pp. 783-786, 1993.

[49] M. J. Schell, R. O. Brady Jr., M. E. Molliver, and S. H. Snyder, "D-serine as a neuromodulator: regional and developmental localizations in rat brain glia resemble NMDA receptors," Journal of Neuroscience, vol. 17, no. 5, pp. 1604-1615, 1997.

[50] M. J. Schell, M. E. Molliver, and S. H. Snyder, "D-serine, an endogenous synaptic modulator: localization to astrocytes and glutamate-stimulated release," Proceedings of the National Academy of Sciences of the United States of America, vol. 92, no. 9, pp. 3948-3952, 1995.

[51] T. Haradahira, T. Okauchi, J. Maeda et al., "Effects of endogenous agonists, glycine and $\mathrm{D}$-serine, on in vivo specific binding of $\left[{ }^{11} \mathrm{C}\right] \mathrm{L}-703,717$, a PET radioligand for the glycine-binding site of NMDA receptors," Synapse, vol. 50, no. 2, pp. 130-136, 2003.
[52] K. R. Gogas, "Glutamate-based therapeutic approaches: NR2B receptor antagonists," Current Opinion in Pharmacology, vol. 6, no. 1, pp. 68-74, 2006.

[53] P. Malherbe, V. Mutel, C. Broger et al., "Identification of critical residues in the amino terminal domain of the human NR2B subunit involved in the RO 25-6981 binding pocket," Journal of Pharmacology and Experimental Therapeutics, vol. 307, no. 3, pp. 897-905, 2003.

[54] F. Menniti, B. Chenard, M. Collins, M. Ducat, I. Shalaby, and F. White, "CP-101,606, a potent neuroprotectant selective for forebrain neurons," European Journal of Pharmacology, vol. 331, no. 2-3, pp. 117-126, 1997.

[55] T. Haradahira, J. Maeda, T. Okauchi et al., "Synthesis, in vitro and in vivo pharmacology of a C-11 labeled analog of CP-101,606, ( \pm )threo-1-(4-hydroxyphenyl)-2-[4-hydroxy-4(p- $\left[{ }^{11} \mathrm{C}\right]$ methoxyphenyl)piperidino]-1-propanol, as a PET tracer for NR2B subunit-containing NMDA receptors," Nuclear Medicine and Biology, vol. 29, no. 5, pp. 517-525, 2002.

[56] H. Mori and M. Mishina, "Structure and function of the NMDA receptor channel," Neuropharmacology, vol. 34, no. 10, pp. 12191237, 1995.

[57] G. Roger, B. Lagnel, L. Besret et al., "Synthesis, radiosynthesis and in vivo evaluation of 5-[3-(4- benzylpiperidin1-yl)prop-1-ynyl]-1,3-dihydrobenzoimidazol-2-[ $\left.{ }^{11} \mathrm{C}\right]$ one, as a potent NR1A/2B subtype selective NMDA PET radiotracer," Bioorganic and Medicinal Chemistry, vol. 11, no. 24, pp. 54015408, 2003.

[58] G. Roger, F. Dollé, B. de Bruin et al., "Radiosynthesis and pharmacological evaluation of $\left[{ }^{11} \mathrm{C}\right]$ EMD-95885: a high affinity ligand for NR2B-containing NMDA receptors," Bioorganic and Medicinal Chemistry, vol. 12, no. 12, pp. 3229-3237, 2004.

[59] T. Fuchigami, H. Yamaguchi, M. Ogawa et al., "Synthesis and biological evaluation of radio-iodinated benzimidazoles as SPECT imaging agents for NR2B subtype of NMDA receptor," Bioorganic and Medicinal Chemistry, vol. 18, no. 21, pp. 74977506, 2010.

[60] F. Dollé, H. Valette, S. Demphel et al., "Radiosynthesis and in vivo evaluation of $\left[{ }^{11} \mathrm{C}\right] \mathrm{Ro}-647312$ : A novel NR1/2B subtype selective NMDA receptor radioligand," Journal of Labelled Compounds and Radiopharmaceuticals, vol. 47, no. 13, pp. 911920, 2004.

[61] E. Årstad, S. Platzer, A. Berthele et al., “Towards NR2B receptor selective imaging agents for PET-synthesis and evaluation of $\mathrm{N}$-[ $\left.{ }^{11} \mathrm{C}\right]$-(2-methoxy)benzyl $(E)$-styrene-, 2-naphthyl- and 4-trifluoromethoxyphenylamidine," Bioorganic and Medicinal Chemistry, vol. 14, no. 18, pp. 6307-6313, 2006.

[62] C. Addy, C. Assaid, D. Hreniuk et al., "Single-dose administration of MK-0657, an NR2B-selective NMDA antagonist, does not result in clinically meaningful improvement in motor function in patients with moderate Parkinson's disease," Journal of Clinical Pharmacology, vol. 49, no. 7, pp. 856-864, 2009.

[63] R. Koudih, G. Gilbert, M. Dhilly et al., "Synthesis and in vitro characterization of trans- and cis- $\left[{ }^{18} \mathrm{~F}\right]-4$-methylbenzyl 4-[(pyrimidin-2-ylamino)methyl]-3- fluoropiperidine-1carboxylates as new potential PET radiotracer candidates for the NR2B subtype N-methyl-d-aspartate receptor," European Journal of Medicinal Chemistry, vol. 53, pp. 408-415, 2012.

[64] N. Pitsikas, "The metabotropic glutamate receptors: potential drug targets for the treatment of anxiety disorders?" European Journal of Pharmacology, vol. 723, no. 1, pp. 181-184, 2014. 
[65] S. Chaki, Y. Ago, A. Palucha-Paniewiera, F. Matrisciano, and A. Pilc, "MGlu2/3 and mGlu5 receptors: potential targets for novel antidepressants," Neuropharmacology, vol. 66, pp. 40-52, 2013.

[66] H.-G. Lee, X. Zhu, M. J. O’Neill et al., "The role of metabotropic glutamate receptors in Alzheimer's disease," Acta Neurobiologiae Experimentalis, vol. 64, no. 1, pp. 89-98, 2004.

[67] P. N. Vinson and P. J. Conn, "Metabotropic glutamate receptors as therapeutic targets for schizophrenia," Neuropharmacology, vol. 62, no. 3, pp. 1461-1472, 2012.

[68] F. Gasparini, T. Di Paolo, and B. Gomez-Mancilla, "Metabotropic glutamate receptors for parkinson's disease therapy," Parkinson's Disease, vol. 2013, Article ID 196028, 11 pages, 2013.

[69] R. T. Ngomba, I. Santolini, T. E. Salt et al., "Metabotropic glutamate receptors in the thalamocortical network: Strategic targets for the treatment of absence epilepsy," Epilepsia, vol. 52, no. 7, pp. 1211-1222, 2011.

[70] F. Nicoletti, J. Bockaert, G. L. Collingridge et al., "Metabotropic glutamate receptors: from the workbench to the bedside," Neuropharmacology, vol. 60, no. 7-8, pp. 1017-1041, 2011.

[71] F. Ferraguti and R. Shigemoto, "Metabotropic glutamate receptors," Cell and Tissue Research, vol. 326, no. 2, pp. 483-504, 2006.

[72] A. Slassi, M. Isaac, L. Edwards et al., "Recent advances in noncompetitive mGlu5 receptor antogonists and their potential therapeutic applications," Current Topics in Medicinal Chemistry, vol. 5, no. 9, pp. 897-911, 2005.

[73] P. J. Conn, C. W. Lindsley, and C. K. Jones, "Activation of metabotropic glutamate receptors as a novel approach for the treatment of schizophrenia," Trends in Pharmacological Sciences, vol. 30, no. 1, pp. 25-31, 2009.

[74] Y. Huang, R. Narendran, F. Bischoff et al., "A positron emission tomography radioligand for the in vivo labeling of metabotropic glutamate 1 receptor: (3-Ethyl-2- $\left[{ }^{11} \mathrm{C}\right]$ methyl6- quinolinyl)(cis-4-methoxycyclohexyl)methanone," Journal of Medicinal Chemistry, vol. 48, no. 16, pp. 5096-5099, 2005.

[75] Y. Huang, R. Narendran, F. Bischoff et al., "Synthesis and characterization of two pet radioligands for the metabotropic glutamate 1 (mGlu1) receptor," Synapse, vol. 66, no. 12, pp. 10021014, 2012.

[76] K. Yanamoto, F. Konno, C. Odawara et al., "Radiosynthesis and evaluation of $\left[{ }^{11} \mathrm{C}\right] \mathrm{YM}-202074$ as a PET ligand for imaging the metabotropic glutamate receptor type 1," Nuclear Medicine and Biology, vol. 37, no. 5, pp. 615-624, 2010.

[77] E. D. Hostetler, W. Eng, A. D. Joshi et al., "Synthesis, characterization, and monkey PET studies of $\left[{ }^{18} \mathrm{~F}\right] \mathrm{MK}-1312$, a PET tracer for quantification of mGluR1 receptor occupancy by MK-5435," Synapse, vol. 65, no. 2, pp. 125-135, 2011.

[78] M. Fujinaga, J. Maeda, J. Yui et al., "Characterization of 1(2-[18F]fluoro-3-pyridyl)-4-(2-isopropyl- 1-oxo- isoindoline-5yl)-5-methyl-1H-1,2,3-triazole, a PET ligand for imaging the metabotropic glutamate receptor type 1 in rat and monkey brains," Journal of Neurochemistry, vol. 121, no. 1, pp. 115-124, 2012.

[79] A. Satoh, Y. Nagatomi, Y. Hirata et al., "Discovery and in vitro and in vivo profiles of 4-fluoro- $N$-[4-[6-(isopropylamino)pyrimidin-4-yl]-1,3-thiazol-2-yl]- $N$-methylbenzamide as novel class of an orally active metabotropic glutamate receptor 1 (mGluR1) antagonist," Bioorganic and Medicinal Chemistry Letters, vol. 19, no. 18, pp. 5464-5468, 2009.

[80] T. Yamasaki, M. Fujinaga, Y. Yoshida et al., "Radiosynthesis and preliminary evaluation of $4-\left[{ }^{18} \mathrm{~F}\right]$ fluoro-N-[4- [6-(isopropylamino)pyrimidin-4-yl]-1,3-thiazol-2-yl]-N-methylbenzamide as a new positron emission tomography ligand for metabotropic glutamate receptor subtype 1," Bioorganic and Medicinal Chemistry Letters, vol. 21, no. 10, pp. 2998-3001, 2011.

[81] T. Yamasaki, M. Fujinaga, J. Maeda et al., "Imaging for metabotropic glutamate receptor subtype 1 in rat and monkey brains using PET with [18F]FITM," European Journal of Nuclear Medicine and Molecular Imaging, vol. 39, no. 4, pp. 632-641, 2012.

[82] T. Yamasaki, M. Fujinaga, K. Kawamura et al., "In vivo measurement of the affinity and density of metabotropic glutamate receptor subtype 1 in rat brain using ${ }^{18}$ F-FITM in small-animal PET,' Journal of Nuclear Medicine, vol. 53, no. 10, pp. 1601-1607, 2012.

[83] M. Fujinaga, T. Yamasaki, J. Yui et al., "Synthesis and evaluation of novel radioligands for positron emission tomography imaging of metabotropic glutamate receptor subtype 1 (mGluR1) in rodent brain," Journal of Medicinal Chemistry, vol. 55, no. 5, pp. 2342-2352, 2012.

[84] J. Yui, L. Xie, M. Fujinaga et al., "Monitoring neuroprotective effects using positron emission tomography with [ $\left.{ }^{11} \mathrm{C}\right] \mathrm{ITMM}$, a radiotracer for metabotropic glutamate 1 receptor," Stroke, vol. 44, no. 9, pp. 2567-2572, 2013.

[85] J. Toyohara, M. Sakata, K. Oda et al., "Initial human PET studies of metabotropic glutamate receptor type 1 ligand ${ }^{11}$ C-ITMM," Journal of Nuclear Medicine, vol. 54, no. 8, pp. 1302-1307, 2013.

[86] M. Fujinaga, T. Yamasaki, J. Maeda et al., "Development of $N$-[4-[6-(isopropylamino)pyrimidin-4-yl]-1,3-thiazol-2-yl] $\mathrm{N}$-methyl-4-[ $\left.{ }^{11} \mathrm{C}\right]$ methylbenzamide for positron emission tomography imaging of metabotropic glutamate 1 receptor in monkey brain," Journal of Medicinal Chemistry, vol. 55, no. 24, pp. 11042-11051, 2012.

[87] T. Yamasaki, J. Maeda, M. Fujinaga et al., "PET brain kinetics studies of ${ }^{11} \mathrm{C}$-ITMM and ${ }^{11} \mathrm{C}$-ITDM, radioprobes for metabotropic glutamate receptor type 1 , in a nonhuman primate," The American Journal of Nuclear Medicine and Molecular Imaging, vol. 4, pp. 260-269, 2014.

[88] T. Yamasaki, M. Fujinaga, J. Yui et al., "Noninvasive quantification of metabotropic glutamate receptor type 1 with $\left[{ }^{11} \mathrm{C}\right] \mathrm{ITDM}$ : a small-animal PET study," Journal of Cerebral Blood Flow and Metabolism, vol. 34, no. 4, pp. 606-612, 2014.

[89] R. Xu, P. Zanotti-Fregonara, S. S. Zoghbi et al., "Synthesis and evaluation in monkey of $\left[{ }^{18} \mathrm{~F}\right] 4$-Fluoro- $N$-methyl- $N$ (4-(6-(methylamino)pyrimidin-4-yl)thiazol-2-yl)benzamide ([ ${ }^{18}$ F]FIMX): a promising radioligand for PET imaging of brain metabotropic glutamate receptor 1 (mGluR1)," Journal of Medicinal Chemistry, vol. 56, no. 22, pp. 9146-9155, 2013.

[90] P. Zanotti-Fregonara, S. Zoghbi, J. S. Liow et al., " $\left[{ }^{18}\right.$ F]FIMX is a promising tracer to quantify metabotropic glutamate receptor 1 (mGluR1) in human brain," Journal of Nuclear Medicine, vol. 55, supplement 1, p. 359, 2014.

[91] T. G. Hamill, S. Krause, C. Ryan et al., "Synthesis, characterization, and first successful monkey imaging studies of metabotropic glutamate receptor subtype 5 (mGluR5) PET radiotracers," Synapse, vol. 56, no. 4, pp. 205-216, 2005.

[92] J.-Q. Wang, W. Tueckmantel, A. Zhu, D. Pellegrino, and A.-L. Brownell, "Synthesis and preliminary biological evaluation of 3$\left[{ }^{18} \mathrm{~F}\right]$ fluoro-5-(2-pyridinylethynyl)benzonitrile as a PET radiotracer for imaging metabotropic glutamate receptor subtype 5," Synapse, vol. 61, no. 12, pp. 951-961, 2007.

[93] D. F. Wong, R. Waterhouse, H. Kuwabara et al., “ ${ }^{18}$ F-FPEB, a PET radiopharmaceutical for quantifying metabotropic glutamate 5 receptors: a first-in-human study of radiochemical 
safety, biokinetics, and radiation dosimetry," Journal of Nuclear Medicine, vol. 54, no. 3, pp. 388-396, 2013.

[94] S. M. Ametamey, L. J. Kessler, M. Honer et al., "Radiosynthesis and preclinical evaluation of ${ }^{11} \mathrm{C}-\mathrm{ABP} 688$ as a probe for imaging the metabotropic glutamate receptor subtype 5," Journal of Nuclear Medicine, vol. 47, no. 4, pp. 698-705, 2006.

[95] S. M. Ametamey, V. Treyer, J. Streffer et al., "Human PET studies of metabotropic glutamate receptor subtype 5 with ${ }^{11} \mathrm{C}$ ABP688," Journal of Nuclear Medicine, vol. 48, no. 2, pp. 247252, 2007.

[96] M. Kågedal, Z. Cselényi, S. Nyberg et al., "A positron emission tomography study in healthy volunteers to estimate mGluR5 receptor occupancy of AZD2066-estimating occupancy in the absence of a reference region," NeuroImage, vol. 82, pp. 160-169, 2013.

[97] K. Kawamura, T. Yamasaki, K. Kumata et al., "Binding potential of $(E)-\left[{ }^{11} \mathrm{C}\right] \mathrm{ABP} 688$ to metabotropic glutamate receptor subtype 5 is decreased by the inclusion of its ${ }^{11} \mathrm{C}$-labelled Z-isomer," Nuclear Medicine and Biology, vol. 41, no. 1, pp. 17-23, 2014.

[98] F. G. Siméon, A. K. Brown, S. S. Zoghbi, V. M. Patterson, R. B. Innis, and V. W. Pike, "Synthesis and simple ${ }^{18}$ F-labeling of 3-fluoro-5-(2-(2- (fluoromethyl)thiazol-4yl)ethynyl)benzonitrile as a high affinity radioligand for imaging monkey brain metabotropic glutamate subtype- 5 receptors with positron emission tomography," Journal of Medicinal Chemistry, vol. 50, no. 14, pp. 3256-3266, 2007.

[99] H. U. Shetty, S. S. Zoghbi, F. G. Simeon et al., "Radiodefluorination of 3-fluoro-5-(2- $\left(2-\left[{ }^{18} \mathrm{~F}\right]\right.$ (fluoromethyl)-thiazol-4yl)ethynyl)benzonitrile ( $\left[{ }^{18} \mathrm{~F}\right] \mathrm{SP} 203$, a radioligand for imaging brain metabotropic glutamate subtype-5 receptors with positron emission tomography, occurs by glutathionylation in rat brain," Journal of Pharmacology and Experimental Therapeutics, vol. 327, pp. 727-735, 2008.

[100] J. J. P. Bogaards, J. C. Venekamp, F. G. C. Salmon, and P. J. Van Bladeren, "Conjugation of isoprene monoepoxides with glutathione, catalyzed by $\alpha, \mu, \pi$ and $\theta$-class glutathione $S$ transferases of rat and man," Chemico-Biological Interactions, vol. 117, no. 1, pp. 1-14, 1999.

[101] A. K. Brown, Y. Kimura, S. S. Zoghbi et al., "Metabotropic glutamate subtype 5 receptors are quantified in the human brain with a novel radioligand for PET,' Journal of Nuclear Medicine, vol. 49, no. 12, pp. 2042-2048, 2008.

[102] Y. Hao, R. Martin-Fardon, and F. Weiss, "Behavioral and functional evidence of metabotropic glutamate receptor $2 / 3$ and metabotropic glutamate receptor 5 dysregulation in cocaineescalated rats: factor in the transition to dependence," Biological Psychiatry, vol. 68, no. 3, pp. 240-248, 2010.

[103] D. Martinez, M. Slifstein, N. Nabulsi et al., "Imaging glutamate homeostasis in cocaine addiction with the metabotropic glutamate receptor 5 positron emission tomography radiotracer $\left[{ }^{11} \mathrm{C}\right] \mathrm{ABP} 688$ and magnetic resonance spectroscopy," Biological Psychiatry, vol. 75, no. 2, pp. 165-171, 2014.

[104] M. S. Milella, L. Marengo, K. Larcher et al., "Limbic system mGluR5 availability in cocaine dependent subjects: a highresolution PET [ $\left.{ }^{11} \mathrm{C}\right] \mathrm{ABP} 688$ study," Neuroimage, vol. 98, pp. 195-202, 2014.

[105] N. E. Paterson and A. Markou, "The metabotropic glutamate receptor 5 antagonist MPEP decreased break points for nicotine, cocaine and food in rats," Psychopharmacology, vol. 179, no. 1, pp. 255-261, 2005.

[106] M. I. Palmatier, X. Liu, E. C. Donny, A. R. Caggiula, and A. F. Sved, "Metabotropic glutamate 5 receptor (mGluR5) antagonists decrease nicotine seeking, but do not affect the reinforcement enhancing effects of nicotine," Neuropsychopharmacology, vol. 33, no. 9, pp. 2139-2147, 2008.

[107] F. Akkus, S. M. Ametamey, V. Treyer et al., "Marked global reduction in mGluR5 receptor binding in smokers and ex-smokers determined by $\left[{ }^{11} \mathrm{C}\right] \mathrm{ABP} 688$ positron emission tomography," Proceedings of the National Academy of Sciences of the United States of America, vol. 110, no. 2, pp. 737-742, 2013.

[108] L. R. Merlin, "Differential roles for mGluR1 and mGluR5 in the persistent prolongation of epileptiform bursts," Journal of Neurophysiology, vol. 87, no. 1, pp. 621-625, 2002.

[109] T. Kirschstein, M. Bauer, L. Müller et al., "Loss of metabotropic glutamate receptor-dependent long-term depression via downregulation of mGluR5 after status epilepticus," The Journal of Neuroscience, vol. 27, no. 29, pp. 7696-7704, 2007.

[110] H. Choi, Y. K. Kim, S. W. Oh et al., "In vivo imaging of mGluR5 changes during epileptogenesis using $\left[{ }^{11} \mathrm{C}\right] \mathrm{ABP} 688$ PET in pilocarpine-induced epilepsy rat model," PLoS ONE, vol. 9, no. 3, Article ID e92765, 2014.

[111] A. Deschwanden, B. Karolewicz, A. M. Feyissa et al., "Reduced metabotropic glutamate receptor 5 density in major depression determined by $\left[{ }^{11} \mathrm{C}\right] \mathrm{ABP} 688 \mathrm{PET}$ and postmortem study," The American Journal of Psychiatry, vol. 168, no. 7, pp. 727-734, 2011.

[112] M. J. Fell, D. L. McKinzie, J. A. Monn, and K. A. Svensson, "Group II metabotropic glutamate receptor agonists and positive allosteric modulators as novel treatments for schizophrenia," Neuropharmacology, vol. 62, no. 3, pp. 1473-1483, 2012.

[113] M. Amalric, S. Lopez, C. Goudet et al., "Group III and subtype 4 metabotropic glutamate receptor agonists: discovery and pathophysiological applications in Parkinson's disease," Neuropharmacology, vol. 66, pp. 53-64, 2013.

[114] N. K. Parelkar and J. Q. Wang, "Upregulation of metabotropic glutamate receptor $8 \mathrm{mRNA}$ expression in the rat forebrain after repeated amphetamine administration," Neuroscience Letters, vol. 433, no. 3, pp. 250-254, 2008.

[115] J. I. Andrés, J. Alcázar, J. M. Cid et al., "Synthesis, evaluation, and radiolabeling of new potent positive allosteric modulators of the metabotropic glutamate receptor 2 as potential tracers for positron emission tomography imaging," Journal of Medicinal Chemistry, vol. 55, no. 20, pp. 8685-8699, 2012.

[116] K. V. Laere, M. Koole, J. Hoon et al., "Biodistribution, dosimetry and kinetic modeling of $\left[{ }^{11} \mathrm{C}\right] J \mathrm{NJ}-42491293$, a PET tracer for the mGluR2 receptor in the human brain," Journal of Nuclear Medicine, vol. 53, supplement 1, article 355, 2012.

[117] D. W. Engers, C. M. Niswender, C. D. Weaver et al., "Synthesis and evaluation of a series of heterobiarylamides that are centrally penetrant metabotropic glutamate receptor 4 (mGluR4) positive allosteric modulators (PAMs)," Journal of Medicinal Chemistry, vol. 52, no. 14, pp. 4115-4118, 2009.

[118] K.-E. Kil, Z. Zhang, K. Jokivarsi et al., "Radiosynthesis of $N$-(4chloro-3- $\left[{ }^{11} \mathrm{C}\right]$ methoxyphenyl)-2- picolinamide ( $\left.\left[{ }^{11} \mathrm{C}\right] \mathrm{ML} 128\right)$ as a PET radiotracer for metabotropic glutamate receptor subtype 4 (mGlu4)," Bioorganic and Medicinal Chemistry, vol. 21, no. 19, pp. 5955-5962, 2013.

[119] M. Nakamura, H. Kurihara, G. Suzuki, M. Mitsuya, M. Ohkubo, and H. Ohta, "Isoxazolopyridone derivatives as allosteric metabotropic glutamate receptor 7 antagonists," Bioorganic and Medicinal Chemistry Letters, vol. 20, no. 2, pp. 726-729, 2010.

[120] M. L. Vallano, B. Lambolez, E. Audinat, and J. Rossier, "Neuronal activity differentially regulates NMDA receptor subunit expression in cerebellar granule cells," Journal of Neuroscience, vol. 16, no. 2, pp. 631-639, 1996. 
[121] K. W. Roche, S. Standley, J. McCallum, C. Dune Ly, M. D. Ehlers, and R. J. Wenthold, "Molecular determinants of NMDA receptor internalization," Nature Neuroscience, vol. 4, no. 8, pp. 794-802, 2001.

[122] T. Hayashi, G. M. Thomas, and R. L. Huganir, "Dual palmitoylation of NR2 subunits regulates NMDA receptor trafficking,"

Neuron, vol. 64, no. 2, pp. 213-226, 2009. 


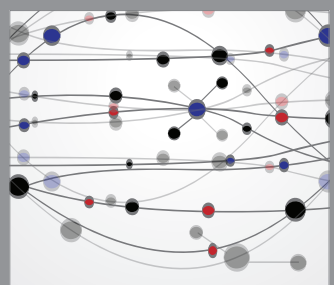

The Scientific World Journal
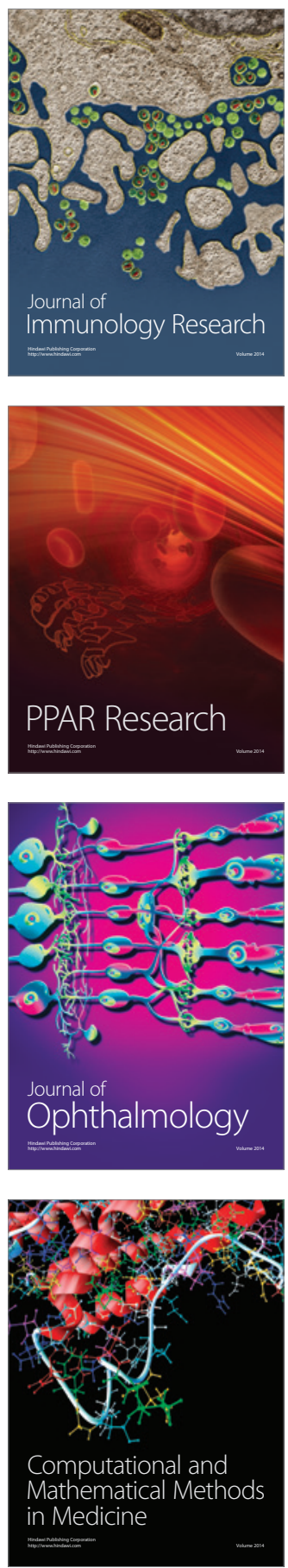

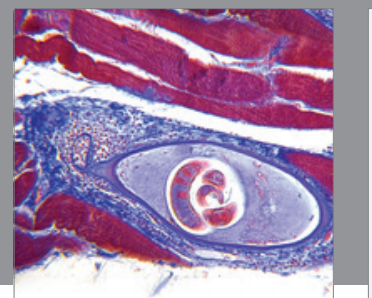

Gastroenterology

Research and Practice
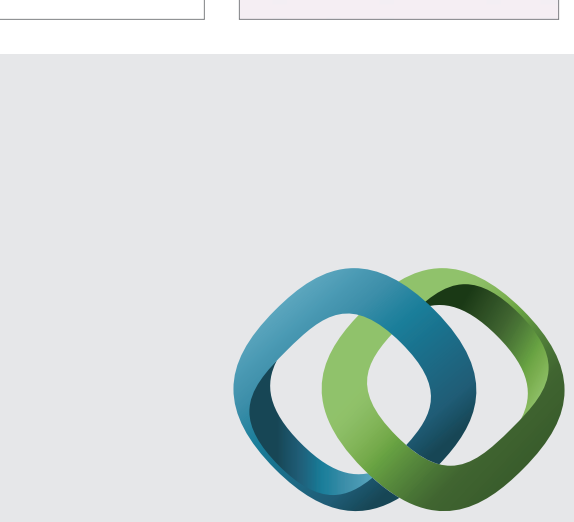

\section{Hindawi}

Submit your manuscripts at

http://www.hindawi.com
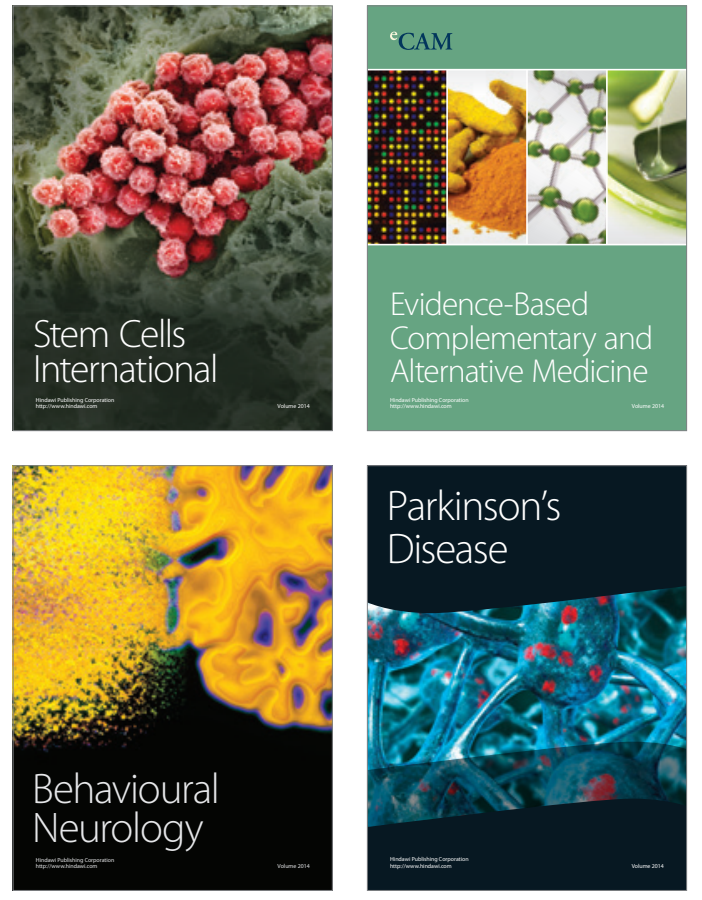
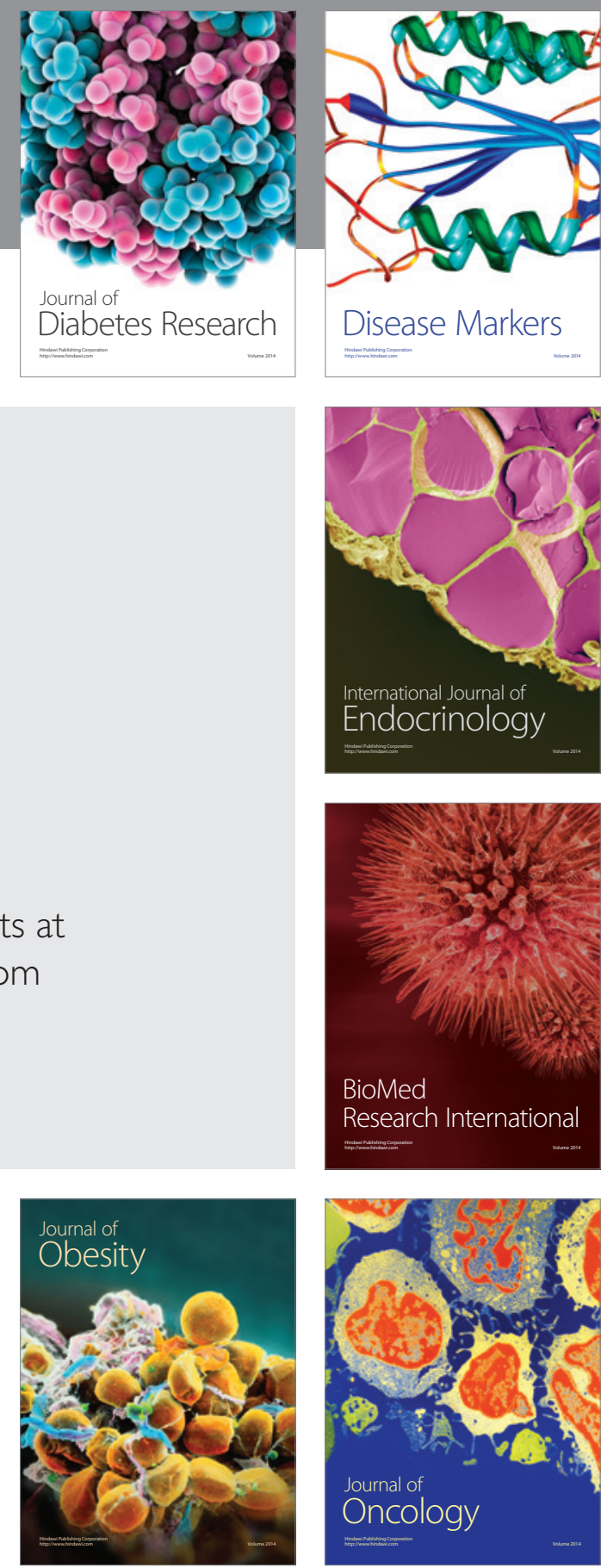

Disease Markers
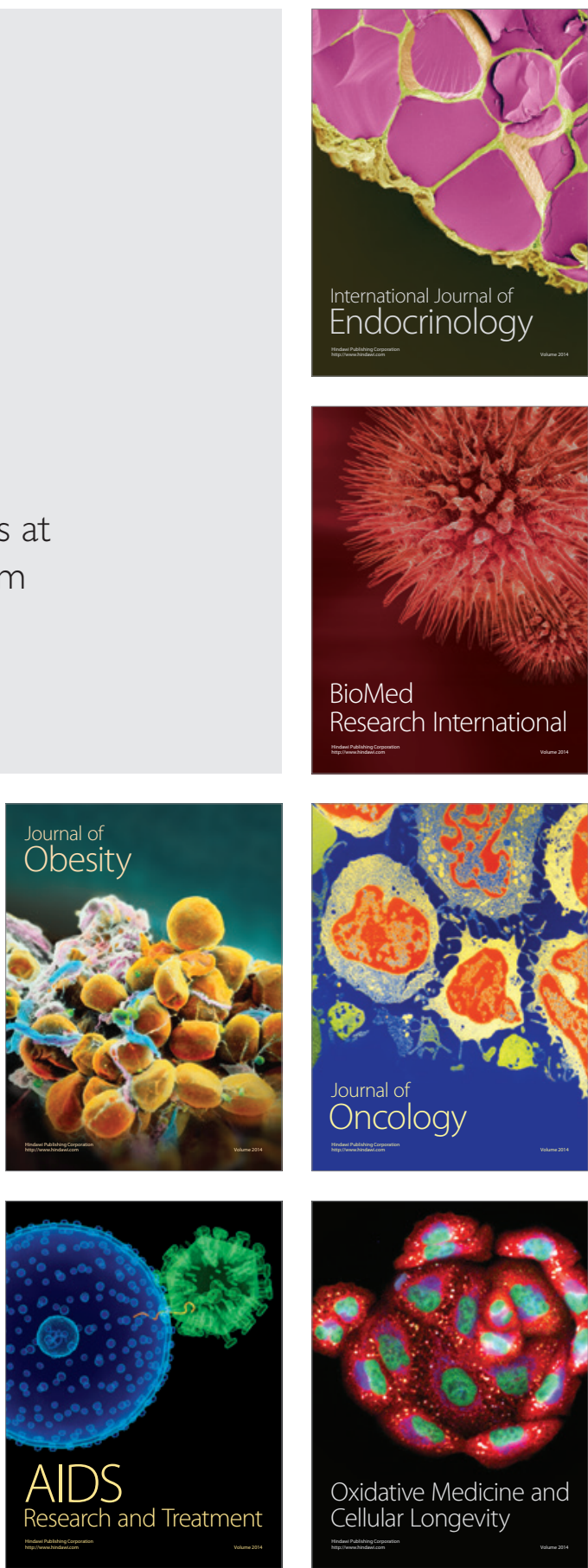